\title{
Mindset Metrics in Market Response Models: An Integrative Approach
}

\author{
Shuba Srinivasan, ${ }^{1}$ Marc Vanhuele, ${ }^{2}$ and Koen Pauwels ${ }^{3}$
}

June 19, 2009

${ }^{1}$ Associate Professor of Marketing, School of Management, Boston University, MA02215, Phone: (617) 353 5978, Fax: (617) 353 4098, E-mail:ssrini@bu.edu.

${ }^{2}$ Associate Professor of Marketing, HEC Paris, 78351 Jouy-en-Josas, France, Phone: +33 139 6772 34, Fax: +33 1396770 87, E-mail: vanhuele@ hec.fr.

3 Associate Professor of Marketing, OzyeginUniversity, Istanbul, and Tuck School of Business at Dartmouth, Hanover, NH 03755, Phone: (603) 646 1097, E-fax: 1502396 5295, E-mail: koen.h.pauwels@dartmouth.edu.

We thank TNS Worldpanel France for providing the data used in this paper and the Marketing Science Institute for financial support. We also thank the Editor, Joel Huber, the Associate Editor and two anonymous reviewers for their helpful suggestions. For insightful comments, the authors thank the participants at the 2007 Marketing Science Conference, the 2008 Yale Collaborative \& Multidisciplinary Research Conference, the 2008 Marketing Dynamics Conference and the research seminars of the McDonough School of Business at GeorgetownUniversity, BilkentUniversity, and the Tuck School of Business at Dartmouth. 


\section{Mindset Metrics in Market Response Models: An Integrative Approach}

\section{Abstract}

Demonstrations of marketing effectiveness currently proceedon two parallel tracks: quantitative researchers model the direct sales effects of the marketing mix, while advertising and branding experts trace customer mindset metrics like awareness and affect. We merge the two tracks and analyze the added explanatory value of including customer mindset metrics in a sales response model that already accounts for short and long-term effects of advertising, price, distribution and promotion. Vector Autoregressive modeling of the metrics for over 60 brands of four consumer goods shows that advertising awareness, liking and purchase consideration account for almost one-third of explainedsales variance. Interestingly, competitive and own mindset metrics make a similar contribution. Wear-in times reveal that mindset metrics can be used as advance warning signals that allow enough time for managerial action before market performance itself is affected. Specific marketing actions impact specific mindset metrics, with the strongest overall impact for distribution. Our findings suggest that modelers should include mindset metrics in sales response models, while branding experts should include competition in their tracking research.

Keywords: customer mindset metrics, market response models, time series models, vector autoregressive models, forecast error variance decomposition, leading indicators. 


\section{Introduction}

"How do you know if you are doing a good job for the customer? It is not shown in your profits this year but in your share of the customer's mind and heart. Companies that make steady gains in mind share and heart share will inevitably make gains in market share and profitability."

--Philip Kotler (2003)

The call for marketing accountability has been growing over the past decade and answering it is seen as key to regaining marketing's standing in the C-suite (Webster, Malter and Ganesan 2003). As a result, marketers have shown a vivid interest in metrics, as evidenced by a series of recent books on the topic (e.g., Davis 2006; Farris, Bendle, Pfeiffer and Reibstein 2006; Lehmann and Reibstein 2006). Most metrics-based quantitative research has focused on linking marketing actions directly to the company's top line, bottom line and stock market performance (Lehmann 2004; Pauwels, Silva-Risso, Srinivasan and Hanssens 2004; Srinivasan and Hanssens 2009). However, there are also recent calls to complement these input and output measures with throughput measures on the perceptions, attitudes and intentions of consumers. Gupta and Zeithaml (2006), for instance, call for research that "incorporates perceptual constructs in behavioral outcome models" (p. 734), and the Marketing Science Institute includes the combining of behavioral and attitudinal data to predict brand performance among its research priorities for 2006-2008.

We will refer to measures on the perceptions, attitudes and intentions of consumers as mindset metrics. They are collected with surveys, often on a regular basis. Mindset metrics are not really popular among quantitative modelers. Gupta and Zeithaml (2006), for instance, observe that "researchers and companies find that they can bypass unobserved metrics" (p. 721). When quantitative modelers establish the short-term and long-term sales and profit effects of the marketing mix (e.g., Hanssens, Parsons and Schultz 2001), they typically treat the customer's mind and heart as a black box. In contrast, mindset metrics are often used by advertising and 
branding experts and by researchers in consumer behavior who examine the influence of marketing actions on the consumer mindset. These experts and researchers typically do not examine the ultimate effect on sales and ignore the impact of competitive actions.

Our main research question is: does including mindset metrics add explanatory power to a sales response model that already includes marketing mix actions? If the answer is 'yes', then subsequent research questions are how large the effects of mindset metrics on salesare, and how large the effects of marketing actions on the mindset metricsare.In addition, it is interesting for managers to know whether mindset metrics can be used as advance warning signals. Our final set of research questions is therefore what the wear-in times of mindset metric changes on sales are and how they compare with the wear-in times of marketing mix actions changes on sales.To answer these research questions, we proceed as follows. We first provide the research framework, followed by a description of the data set with comprehensive information on performance metrics, marketing mix metrics and mindset metrics for over 60 brands in four fastmoving consumer goods categories on a four-weekly basis over a period of 7 years. Next, we describe the estimation methodology of Vector Autoregressive (VARX) models which allows us to address endogeneity by incorporating lagged effects and complex feedback loops that are typical with this type of data (Dekimpe and Hanssens 2007). We then present our empirical findings on integrating mindset metrics into market response models. Finally, we conclude the paper with the limitations of our study and several directions for future research.

\section{Research Framework}

Mindset metrics have a long history in marketing, especially in the advertising world. Russell Colley's work (1961) had much influence on the advertising planning process by focusing advertisers' attention on communication-based measures, which correspond to our mindset metrics, as opposed to sales-based objectives. Mindset metrics are also the building blocks of the hierarchy-of-effects model of advertising (Palda 1966; Vakratsas and Ambler 
1999). The central idea of this model is that each advertisement exposure moves the consumer forward through a hierarchical sequence of events, including cognition (e.g. awareness, knowledge), affect (e.g. liking, desire) and, ultimately, behavior (purchase, sometimes measured as purchase intention). More recently, mindset metrics and the idea of this hierarchical sequence have also been used in the evaluation of brand performance from a customer's perspective. In using mindset metrics to track brand performance, brand experts examine not just the effect of advertising but that of the entire marketing mix. Keller and Lehmann (2006), for instance, propose five aspects of customer-based brand equity measurement: awareness, associations, attitude, attachment and action.

Mindset metrics are, however, also controversial. Palda (1966) was probably the first to express his concerns when he wondered if it was really worth the trouble of collecting intermediate measures: "Is it, on balance, really more difficult and expensive to investigate the direct link between advertising expenditure and sales, than it is to undertake research into each step of the hierarchy...?" (ibid, p. 23). Likewise, Boyd, Ray and Strong (1972) argued that if communication metrics ultimately are predictive of sales, which they should be, then sales should be measured directly instead. Even today, mindset metrics remain associated mostly with an advertising world that does not want to be held accountable for sales based on the argument that sales response models only capture short-term effects and miss the long-term sales benefits of brand building.

On the other side, advocates of mindset metrics have hailed them as early signals of performance successes and problems of brands (Ambler 2003; Pauwels and Joshi 2008). Their main argument is that, if marketing actions move customers closer to the buying decision in a series of mental steps, then tracking and interpreting the corresponding mindset metrics provides early evaluation signals (LaPointe 2005). Specific actions that strengthen the competitive position of the brand in customers 'hearts and minds' may not translate into sales immediately but mindset metrics can verify that marketing moves customers in the right direction (Keller and 
Lehmann 2006). In the case of performance problems, the consumer may not react immediately by switching to another brand, but mindset metrics may diagnose a declined interest and offer a chance for remedial action before the bottom line is affected. In addition, it may be difficult to convince consumers to switch back and be easier to instead intervene before they actually leave for greener pastures.

In the introduction we referred to several calls for the integration of input, throughput and output metrics in sales models.Figure 1 summarizes our research framework in visual form. Note that, conceptually, no purchase can occur without the consumer's mind being involved. Therefore, continuous individual consumer tracking of all relevant mindset metrics should capture all marketing effects. In practice, however, mindset metrics cannot catch the full dimensionality and scope of the complex consumer mindset. An empirical model may therefore pick up sales effects of marketing actions that do not (yet) register in changes to the observed set of mindset metrics.

--- Insert Figure 1 about here ---

As evident from Figure 1, no extant method comprehensively incorporates all these metrics simultaneously in assessing sales response. Advertising campaign tests typically consider only what marketers do and what customers think and feel (Belch and Belch 2004). Brand health tracking studies typically only pay attention to what customers think and feel (Keller 2003). Market response models typically address only the first and the third box in Figure 1, focusing on what marketers and customers do (e.g. Hanssens et al. 2001). The objective of our study is to examine whether it is in practice useful to combine all three groups of metrics into an integrative modeling framework.

We do not formulate hypotheses on the exact nature of the relations among mindset metrics themselves. ${ }^{1}$ The VARX models we use for our analysis allow for "multiple hierarchies" and for the idea that the impact of a marketing action on the customer mindset is neither immediate nor simultaneous but occurs in "situationally varying and complex patterns of 
temporal precedence" (Batra and Vanhonacker 1988, p.24). Indeed, both prior brand experience and marketing actions such as advertising can be expected to build connections in consumer memories, resulting in subsequent purchase behavior after some time. Our framework therefore allows for feedback effects of brand performance on the consumer mindset and on the firms' marketing decisions. In addition, the flexible nature of our econometric specification allows us to uncover new insights on the wear-in and wear-out time.

\section{Data}

We use French data from Prométhée, a brand performance tracker developed by TNS Worldpanel, which reports the metrics in which we are interested for four-weekly periods. Prométhée presents a comprehensive, state-of-the-art brand dashboard, with the marketing mix, mindset metrics, and performance metrics. Its key features include a synchronized data collection process and an identical definition of which products belong to each brandacross data sources. The details on the four data sources that TNS integrates are as follows:

1. A nationally representative panel of households is surveyed weekly on aided brand awareness, aided advertising awareness, liking, inclusion in the consideration set, and purchase intentions at the brand level in a given product category. For each product category, more than 8,000 surveys are collected each year, but any given household is interviewed at most twice per year. Prométhée reports four-week averages of the weekly responses for each indicator.

2. A nationally representative household panel with 12,000 members is used to measure purchases and prices paid. To avoid mere measurement biases (Morwitz, Johnson, and Schmittlein 1993), this panel is different from the survey panel. The use of a household panel for purchases and prices paid assures complete coverage of all retail chains in this market, including hard discounters. Households use a handheld scanner to scan each UPC and manually enter the price paid from the receipt. Based on the UPC, Worldpanel 
determines the volume or weight purchased in order to aggregate across different products and package sizes to determine brand sales volume. The price is therefore a price per volume or weight unit.

3. A panel of 500 distribution points is used to track distribution presence and promotional actions. Store presence is determined for each UPC. A value-weighted overall distribution presence is then calculated at the brand level in the form of a percentage. Stores are weighted for their sales in the product category, and each UPC is weighted for its contribution to sales. Promotion is measured as the average percentage of valueweighted distribution that is on promotion for a given observation period. The following forms of promotion are registered: in-store communication, presence of in-store flyers, price promotions, and bonus buys.

4. To measure advertising support, two sources are combined. Some media agencies transmit the expenses directly to TNS (e.g., for billboards). For media that are not covered with this method (e.g., TV), all advertisements are identified. Media space prices are publicly available, which then allows TNS to make the conversion from the number of advertisements and their duration to communication expenses. These expenses are aggregated across four weeks, based on the date of the advertisement (TV) or the date of the media support availability (press).

For the period between January 1999 and May 2006, we have a complete set of observations on 74 brands from 4 categories, differing on the food versus non-food dimension and in terms of storability: breakfast cereals ( 21 brands), bottled water (19 brands), fruit juice (19 brands), and shampoo (21 brands). The data frequency is four weeks, amounting to 96 observations per brand per measure. As focal brand performance measure, we use sales volume ${ }^{2}$ aggregated across all product forms of each brand (in milliliters for shampoo, water, and fruit juice, and grams for cereal), but we also verify the robustness of our results by replicating our analysis with market 
share and revenues. For the marketing mix, our data includes average price paid, value-weighted distribution coverage, promotion, and total spending on advertising media.

After discussion with the data provider, we selected the following three measures from the available consumer mindset metrics: advertising awareness, brand liking, and inclusion in the consideration set. This selection aimed at covering the three main stages of the hierarchy of effects: cognition, affect, and conation. Aided brand awareness, another available measure, showed too little variation due to ceiling effects while purchase intention was too closely correlated with consideration set.

For advertising awareness, survey respondents indicated, in a list of all brands present on the market, those for which they "remember having seen or heard advertising in the past two months." Our measure gives the percentage of respondents who were aware. Liking is measured on a five-point scale ("like enormously," "a lot," "a little," "not really," "not at all"), and the measure we use is the average rating. For the consideration set, respondentswere asked to indicate in a list with all brands on the market "the brands that you would consider buying." We use the percentage of respondents who consider buying as measure.

We also include competitive prices, distribution, promotion, and advertising operationalized as the market-share weighted $^{3}$ prices, distribution, promotion, and advertising of the other brands (other than the focal brand) in the category, as recommended by Dekimpe and Hanssens (1999) and Slotegraaf and Pauwels (2008).

Overall this data set with a temporal duration of over seven years, a presence of different players with different strategies in different product categories, and wide coverage of the marketing-mix as well as consumer mindset metrics, is uniquely suited to address our research questions on the impact of mindset metrics on brand performance. Another important feature, from a measurement perspective, is that all four data sources use an identical definition of the observation periods and the brands. Table 1 provides descriptive statistics on our data, while Figure 2 plots, for each mindset metric, the brand with the median amount of variation on that 
metric.At the level of the individual brand, we observe sufficient variation in each mindset metric over time to relate it to both marketing actions and to brand sales. This benefit likely results from both the long time span of our data ( 7 years versus the standard 3 years) and from the four-weekly (versus weekly) data interval.

--- Insert Table 1 and Figure 2 about here ---

\section{Mindset Metrics in Market Response Models - Research Methodology}

The dynamic interactions and feedback effects in Figure 1 are captured in VARX models (Dekimpe and Hanssens 2007). First, the endogenous treatment of marketing actions implies that they are explained by both past marketing actions and past performance variables. Second, VARX models are able to capture complex feedback loops that may impact brand performance over time. For instance, an increase in advertising in a given week may generate a high level of advertising awareness, inducing some consumers to consider the brand and try it, after which they develop brand liking. Their subsequent purchases may not only increase brand sales, but also consideration by their family, friends and colleagues who see them use the brand. Because of such chains of events, the full performance implications of the advertising may extend well beyond the immediate effects. By capturing these feedback loops, VARX estimation yields a comprehensive picture of the full dynamic system including marketing actions, mindset metrics and sales performance.

Our empirical time-series analysis proceeds in two steps that are applied to each brand separately. First, we estimate the dynamic interactions among sales, advertising awareness, brand liking, brand consideration, the marketing mix (price, promotions, distribution and advertising), and the corresponding competitive mindset and marketing-mix metrics using VARX models. ${ }^{4}$ Second, Generalized Forecast Error Variance Decomposition (GFEVD) and Generalized Impulse Response Functions (GIRF) are used to quantify the relative influence of marketing actions versus our consumer mindset measures on sales. Finally, we quantify the extent to which 
marketing-mix actions drive the mindset metrics. Table 2 provides references that detail each step.

--- Insert Table 2 about here ---

Step 1: Vector-autoregressive model specification

We estimate a 15-equation VARX model per brand, where the endogenous variables are sales, the three mindset variables (advertising awareness, brand liking, brand consideration), four marketing mix variables (average retail price, advertising, distribution, promotion) and the seven corresponding competitive variables. In matrix notation the model given is by,

$$
Y_{t}=\mathrm{A}+\sum_{i=1}^{p} \Phi_{i} Y_{t-i}+\Psi X_{t}+\Sigma_{t}, \quad t=1,2, \ldots, T
$$

where $\mathrm{A}$ is a $15 \times 1$ vector of intercepts, $Y_{t}$ is an $15 \times 1$ vector of the endogenous variables listed above, $X_{t}$ is a vector of exogenous control variables: (a) a deterministic-trend $t$ to capture the impact of omitted, gradually-changing variables, and (b) quarterly dummy variables to account for seasonal fluctuations in sales or any other endogenous variable. $\Sigma_{t}$ is the covariance matrix of the residuals while subscript $i$ denotes the brand and $p$ is the number of the lags in the model. As benchmark models, we estimate (a) the 9-equation benchmark VARX model obtained by deleting the six mindset metric equations from the full VARX model and (b) the 7-equation VARX model obtained by deleting the eight marketing mix equations from the full VARX model. We provide the details of these models, including details on the parameter-to-observation ratios in Technical Appendix A.

\section{Step 2a: Generalized Forecast Error Variance Decomposition (GFEVD)}

VARX estimation is only the first step needed to answer our research questions. Based on the VARX parameters, we derive GFEVD estimates to investigate whether, and to what extent, mindset metrics explain brand sales performance beyond the impact of marketing mix actions. 
GFEVD quantifies the dynamic explanatory value on sales of each endogenous variable. Akin to a 'dynamic $\mathrm{R}^{2}$, GFEVD provides a measure of the relative impact over time of shocks initiated by each of the individual endogenous variables in a VARX model, without the need for the researcher to specify a causal ordering among these variables (Pesaran and Shin 1998; Nijs et al. 2007). GFEVD estimates are derived using the following equation:

$$
\theta_{i j}^{g}(n)=\frac{\sum_{l=0}^{n}\left(\psi_{i j}^{g}(l)\right)^{2}}{\sum_{l=0}^{n} \sum_{j=0}^{m}\left(\psi_{i j}^{g}(l)\right)^{2}}, i, j=1, \square, m .
$$

where $\psi_{i j}^{g}(l)$ is the value of a Generalized Impulse Response Function (GIRF) following a oneunit shock to variable $i$ on variable $j$ at time $l$ (Pesaran and Shin 1998). ${ }^{5}$ Importantly, the GFEVD attributes $100 \%$ of the forecast error variance in sales to either (a) the past values of the other endogenous variables or (b) the past of sales itself, also known as 'purchase inertia' ${ }^{6}$ The former (e.g. a past change in advertising awareness drives current sales) is much more managerially and conceptually interesting than the latter (a past change in sales drives current sales, but we do not know what induced that past change in sales). Therefore, we assess the dynamic explanatory value of the mindset metrics by the extent to which they increase the sales forecast error variance explained by the potential drivers of sales (i.e. other endogenous variables) in the model, and thus reduce the percentage explained by past sales.

The relative importance of the drivers is established based on the GFEVD values at 6 months, which reduces sensitivity to short-term fluctuations. ${ }^{7}$ To establish the statistical significance of the GFEVD estimate (at the $\mathrm{p}<0.05$ level), we obtain standard errors using Monte Carlo simulations (see Benkwitz et al. 2001). While GFEVD is the appropriate method to assess our main research question, it does come at a cost: it only allows comparable analyses of brands with stationary sales volumes ( $84 \%$ in our dataset). Stationarity implies that, despite the fact that a shock to sales can cause large fluctuations (variance) over time, its effect ultimately dies out and the sales series reverts back to its deterministic (mean + trend + seasonality) pattern. 
The variance of such stationary sales series is finite and time-invariant. In contrast, the variance of an evolving sales volume series (implying shocks have permanent effects) is time-dependent and theoretically (as $t$ approaches infinity) infinite (Pesaran and Shin 1998; Srinivasan, Pauwels and Nijs 2008).

We apply GFEVD for (a) the full VARX model in equation (1), (b) the restricted VARX model which omits the mindset metrics and thus corresponds to the typical VARX-models estimated in previous marketing literature and (c) the restricted model which omits the marketing mix variables. A comparison of the GFEVD results across these models allows us to assess whether mindset metrics (marketing mix variables) yield additional explanatory power in a model that already accounts for long-term effects of marketing-mix variables (mind set metrics) on sales performance and their dynamic interactions.

\section{Step 2b: Generalized Impulse Response Functions (GIRF)}

Our remaining questions are examined by inspecting the Generalized Impulse Response functions based on the estimated parameters of the full VARX model. Based on all these parameters, the impulse response function estimates the net result of a "shock" to a marketing variable on the performance variables relative to their baselines (their expected values in the absence of the marketing shock). Specifically, we measure the long-term performance (brand sales) response to a one-unit shock (Pauwels et al. 2002; Nijs et al. 2001; Srinivasan et al. 2004). We estimate Generalized IRFs with the simultaneous-shocking approach (Evans and Wells 1983; Dekimpe and Hanssens 1999), in which the information in the residual variance-covariance matrix of Equation (1) is used to derive a vector of expected instantaneous shock values. The advantage of this approach is that it does not require selecting a temporal ordering among the variables of interest. Standard errors are subsequently derived using the Monte Carlo simulation

approach with 250 runs in each case (see Horváth 2003) to establish the statistical significance of the parameters (at the $\mathrm{p}<0.05$ level). 
We derive the following three summary statistics from each GIRF: (a) the immediate performance impact on brand sales, which is readily observable to managers, and may therefore receive considerable managerial scrutiny; (b) the permanent impact (i.e., the value to which the IRF converges); and (c) the total or cumulative impact, which combines the immediate effect with all effects across the dust-settling period. In the absence of permanent effects, this total impact becomes the relevant metric to evaluate performance outcomes (Pauwels et al. 2002; Pauwels and Srinivasan 2004). Finally, we obtain the wear-in time of each driver's effect on sales as the period with the highest (in absolute value) impulse response coefficient (Pauwels and Hanssens 2007). Though VARX models, GFEVD and GIRFs have recently been introduced to the marketing literature (e.g. Bronnenberg, Mahajan, and Vanhonacker 2000; Nijs et al. 2001, 2007), this is their first use, to the best of our knowledge, to measure the contribution of mindset metrics to brand performance.

\section{Findings}

The unit root tests classify 62 of the 74 performance series as stationary.As explained in the methodology section, we focus on these 62 brands ( $84 \%$ of all brands) in our analysis. To report our findings, we averaged results across all brands or across all brands of each category.

\section{Mindset metrics matter in market response models}

For both the full model in equation (1) and the restricted benchmark models without mindset metrics and marketing mix actions, we report in Table 3 (columns titled "Summary") their GFEVD results.

\section{--- Insert Table 3 about here --}

In the benchmark model with only marketing mix variables, own and competitive marketing mix account for $26.3 \%$ and $13.4 \%$, respectively, of the total variation in brand sales. The remaining $60 \%$ of the variation in brand sales is attributed to the own past of the sales series, 
also known as purchase inertia. The average (adjusted) $\mathrm{R}^{2}$ for brand sales is $0.57(0.53)$. In the benchmark model with only mindset metrics, own and competitive mindset metrics account for $15.3 \%$ and $10.4 \%$, respectively, of the total variation in brand sales. The remaining $74.3 \%$ of the variation in brand sales is attributed to purchase inertia. The average (adjusted) $\mathrm{R}^{2}$ for brand sales is $0.54(0.50)$. The lower explained variance in this second benchmark model is consistent with our earlier discussion of the practical limitations of mindset metrics: any set of metrics (including ours) is unlikely to fully capture all sales effects of marketing actions. ${ }^{8}$ The brand-specific findings on the adjusted $\mathrm{R}^{2}$ for the estimated models are provided in the web-based Appendix A (Tables A1, A2 and A3).Figure 3 visualizes the explanatory power $\left(\mathrm{R}^{2}\right)$ for the benchmark model withmindset metrics only, the benchmark model withmarketing mix only, and the full model for each category.

\section{--- Insert Figure 3 about here ---}

Having established the better explanatory power of the full model, we use its GFEVD results to address our main research question. Own marketing actions account for $23.1 \%$ while competitive marketing mix accounts for $13.8 \%$ of the variation in brand sales. The three consumer mindset metrics together account for $8.4 \%$ of the variation while competitive mindset metrics account for an additional $7.9 \%$ of the variation in past sales. Thus, mindset metricsown and competitive - together account for $16.3 \%$ of the variation in brand sales. The percentage of variation attributed to inertia thus goes down from $60 \%$ to $46.8 \%$ when mindset metrics are accounted for in the model. Moreover, the full model outperforms the restricted benchmark models in explaining brand sales with an average (adjusted) $\mathrm{R}^{2}$ of 0.67 (0.61). Table 3 also points to the importance of competitive mindset metrics, which contribute almost as much to sales variation as own mindset metrics do (7.9\% versus $8.4 \%)$. In contrast, competitive marketing mix actions contribute only half as much as own marketing actions, $(23.1 \%$ versus $13.8 \%$ ) consistent with the marketing-mix modeling literature (e.g. Van Heerde et al. 
2008).Thus, it appears crucial to measure the 'share of minds and hearts' of competitors together with one's own if mindset metrics are used to explain performance.

In sum, the answer to our first research question is yes, mindset metrics help to explain sales even in a model that accounts for long-term effects of own and competitive marketing mix actions.

We also verified whether our findings generalize to other performance metrics than sales volume and ran robustness checks with brand market share and brand revenue that we report in the last two columns of Table 3 . The results are remarkably similar and we conclude that our finding on the contribution of mindset metrics versus marketing mix in explaining brand performance does not depend on the performance metrics chosen.

Sales response elasticities of consumer mindset metrics versus marketing mix actions

Having established that both marketing-mix and mindset metrics contribute towards explaining sales, we examine whether we find general patterns in the response elasticities across brands. ${ }^{9}$ Table 4 reports both immediate and total (i.e. cumulative) elasticities.

--- Insert Table 4 about here ---

For own brand elasticities, marketing mix actions (mindset metrics) obtained significant sales effects in $81 \%$ (58\%) of all cases (taking $\mathrm{p}<0.05$ as a criterion), as shown in the last two columns of Table 4. For competitive elasticities, marketing mix actions (mindset metrics) obtained significant sales effects in 55\% (49\%) of all cases $(\mathrm{p}<0.05)$. Thus, a higher proportion of own-brand effects relative to competitive effects attained significance, as is common in aggregate response models (Hanssens et al. 2001). We focus on interpreting the own brand elasticities because these represent the levers that managers can pull to enhance their brand's performance. Table 4 shows the own effects of marketing-mix and consumer mindset metrics on 
brand sales, averaged over all estimates. The detailed elasticity estimates are provided in the web-based Appendix A (see Table A4).

Regarding the marketing mix, overall, we find that brand sales are most responsive to distribution, followed by prices, promotions and then advertising. The cumulative distribution elasticityis2.424. This is similar to the single estimate (1.868) available from past literature on frequently purchased consumer goods (Lambin 1976). Our 'dominance of distribution' results for existing brands complement Ataman et al.'s (2008) finding that access to distribution plays the most important role in the success of a new brand. These findings collectively support Hanssens et al.'s (2001) argument that “distribution is one of the most potent marketing contributors to sales and market share" and note that "its elasticity can be substantially greater than one" (p. 347).

As for price, promotions and advertising, the relative magnitude of the estimated elasticities follow those of previous studies. The estimates themselves, based on our French data, differ somewhat from empirical generalizations, mostly based on US data. First, the cumulative sales elasticity for price is -1.734 . Given that these are based on four-weekly data, the magnitude of these price elasticities is in line with Tellis (1988) and Bijmolt, van Heerde and Pieters (2005) who report own-price elasticities of about -2.50 . Second, promotions, a variable that combines four different promotional instruments, has a cumulative elasticity of 0.277 . This elasticity compares to other studies that separate promotional elasticity from price elasticity: Ailawadi, Lehmann and Neslin (2001) report a coupon elasticity of 0.125, while Pauwels (2004) report a feature elasticity of 0.111 and a display elasticity of 0.014 . Finally, the cumulative advertising elasticity is 0.036 , with the order of magnitude similar to the advertising elasticities of 0.05 reported as Empirical Generalizations (EGs) in the literature (e.g. Hanssens et al. 2001; Tellis 2004; Tellis and Ambler 2007). 
Turning to the issue of how large the effects of consumer mindset metrics on sales are, our results show that liking has the highest cumulative sales elasticity (0.590). Consideration (0.374) and advertising awareness (0.289) follow.

\section{Effect timing of consumer mindset metrics versus marketing mix actions}

While it is important to know that consumer mindset metrics explain sales, managers also need time to act upon them, for instance to avoid that a drop in liking translates into a sales decline. A relevant measure to examine this question is the wear-in time, which is the lag before the peak impact on sales is reached (Pauwels 2004). Table 5 shows the wear-in time results.

\section{--- Insert Table 5 about here ---}

As for the marketing mix, the mean wear-in time is shortest for promotions $(1.02$ months), then for price (1.59 months), consistent with previous marketing literature. While promotions give consumers incentives to act faster (Blattberg and Neslin 1990), regular price

changes do not evoke such sense of urgency (Van Heerde et al. 2004). Wear-in is even longer for advertising (1.83 months), the marketing action for which the concept of wear-in time was noted first (Little 1979). A new finding is that the wear-in time for distribution is the highest $(2.12$ months) among the analyzed marketing actions. Plausibly, consumers take some time to notice and then act on increased availability.

Compared to the marketing mix actions, mindset metrics typically take longer to reach their peak impact on sales. The wear-in time for advertising awareness is about 2.32 months, while those for consideration and liking reach 2.23 and 2.00 months, respectively. Juxtaposed with the result that these mindset measures have significant impact on brand sales performance, our findings suggest that collecting and monitoring these mindset metrics is worthwhile for advance warning purposes. For example, if there is a drop in consideration (with a 2.2 month wear-in time), managers can take remedial action with a change to price or promotions which have a shorter wear-in time (of 1.6 months or less) to prevent any adverse brand performance 
impact. Likewise, drops in liking may be counteracted by increasing gross rating points and improving the ad copy. Such empirical knowledge may in fact be critical to the development of effective marketing control systems that are capable of improving long-term brand performance (Rust et al. 2004). Overall, our results underscore the strategic importance of consumer mindset metrics as leading indicators of brand performance.

\section{Which marketing actions drive which mindset metrics?}

While our model allows for dual causality (e.g. between a marketing action and a mindset metric), we focus on the effect of marketing actions on mindset metrics because (a) Granger causality tests revealed that this causality direction was present for a majority of the brands and (b) marketing actions are more directly under management control. To the best of our knowledge, this is the first quantification of the response elasticities of consumer mindset metrics to marketing mix actions. As with the results in Table 6, we focus our attention on own effects while cross effects with competition are included as control variables in the VARX model. Table 6 reports both the immediate and cumulative elasticities averaged over all the estimates. We focus our discussion on the cumulative effects.

--- Insert Table 6 about here ---

Again, we observe the dominance of distribution, which shows the highest cumulative impact on each of the three mindset metrics. First, the cumulative elasticities with respect to distribution are 0.887, 1.040and 0.517 for advertising awareness, for consideration, and for liking, respectively. Thus, consumers report more advertising awareness for brands they can observe in the store, which indicates that distribution helps trigger memory links (Alba et al. 1991). Moreover, they appear to like available brands more and give greater consideration to them. Next, advertising has the highest cumulative impact on advertising awareness (0.064), promotions on consideration (0.032), and price on liking (-0.277). Thuswhile distribution dominates other marketing mix actions in terms of moving the needle on the mindset metrics, each marketing 
action may be deployed selectively to improve a specific mindset metric. Advertising and promotions intuitively increase respectively advertising awareness and consideration. In contrast, our finding that price negatively impacts liking is relatively new (Keller and Lehmann 2006), and may represent the 'more for less' attitude of the $21^{\text {st }}$ century consumer (Kotler and Keller 2006).

\section{Conclusions, Limitations and Future Research}

\section{Conclusions}

Increasing demands for marketing accountability have created a new sense of urgency for marketers to obtain and analyze the right metrics to drive performance growth and demonstrate marketing's value in a consistent manner. The results of our study imply that mindset metrics should be given new consideration. While these metrics have shown their value as diagnostic measures in many companies (e.g. to track brand health), our results indicate that they also explain future sales performance, over and above the part explained by marketing mix actions. Across the four product categories and 62 brands examined, the contribution of mindset metrics is substantial with almost one-third of the total explained sales variance that can be attributed to these metrics. Our findings therefore help marketing executives make a case to top management and analysts that building share in the 'customer's mind and heart' indeed translates into improved marketplace performance. The importance of this demonstration is apparent from the current doubts on the empirical and managerial value of incorporating customer mindset metrics in an integrated market response model.

Classical marketing response models assume that mindset metrics are redundant information in a model that measures how sales react to marketing actions. According to this assumption mindset metrics are just an intermediate step in the model and can as well be treated as a black box. Our demonstration that mindset metrics do matter begs the question of where this additional explanatory power comes from. In all likelihood, the contribution of mindset metrics 
reflects the effect of variables that are not included in the marketing-sales response models. Maybe the most prominent of these omitted variables are those that influence the brand experience and the quality of this experience. Product quality, degree of innovation, brand image, etc. are typically not included in market response models, partly because they are difficult to measure reliably and in a consistent way across different product categories.

A second important result is that mindset metrics are not just interesting for retrospective analyses of sales performance. Through our quantification of the wear-in time of the marketing mix variables and consumer mindset metrics on sales, we conclude that the analyzed mindset metrics can be used on an ongoing basis as early warning signals. Remedial action may then prevent performance decline or turn it around. The estimated wear-in times can in addition help answer more tactical questions such as "when can we pull the plug on an apparently ineffective marketing action?"

If they become replicated across different settings, our analyses also provide some key results on the effectiveness of the marketing mix that have important implications for the effective deployment of marketing actions. The importance of distribution for mature brands in fast-moving consumer goods is evident from an elasticity size that by far dominates that of the rest of the mix. Even when available, distribution is often not incorporated in marketing mix models due to its low variation in the typical 3-year weekly marketing datasets for mature brands (e.g. Pauwels 2004). To uncover long-term effects, it is important to examine longer data periods (our data set covers seven years). Another interesting result is that advertising awareness, consideration, and liking are each driven by all four elements of the marketing mix, with again a dominance of the distribution effect. If the impact of distribution changes is the largest, it is also the slowest with a maximum effect only registered after two months. Advertising in our study takes seven weeks to reach its peak sales effect, not the several quarters or even years sometimes espoused by ad agencies (Tellis 2004). 
For marketing researchers, our findings indicate the value of incorporating perceptual constructs in behavioral outcome models. First, such integrated models have better fit in explaining the 'hard' market place performance of interest, whether it is measured as sales volume, market share or revenue. Second, these models allow for richer insights and more actionable recommendations to marketing managers. Company performance metrics (including financial criteria), marketing expenses and consumer mindset metrics all have their place in the complicated puzzle of marketing effectiveness (Pauwels et al. 2009).

\section{Limitations}

The current study has several limitations, which qualify the generalizability of the results. First, we only investigate 3 mindset metrics: advertising awareness, consideration and liking. Adding metrics on brand usage and memories to the equation may further increase the explanatory power of the model. Second, because both mindset metrics and advertising are available for 4-weekly periods, we use this largest time interval for all variables. If certain variables (e.g. prices) vary more frequently than others, this could dampen their estimated influence. Third, our data sample covers one country and four fast-moving consumer good categories. We compared, when available, our results with those of previous research and the consistency strengthened our confidence that the usefulness of mindset results in explaining sales is not idiosyncratic to France. However, the reported elasticities may differ across countries. Fourth, we do not know the cost of purchasing mindset metrics or the profits that may be generated by brand managers using them. Thus, we cannot assess whether the benefits of using mindset metrics exceeds the cost of collecting or purchasing them. Fifth, we aggregate across stores, which could induce bias - though to a lesser extent in the linear models we use (Christen et al. 1997). Likewise, our aggregation across customers should be further investigated: the finding that increases in average liking improve brand sales does not necessarily imply that increases in liking improve brand 
purchases of each individual consumer (for instance, non-linear effects may apply at the individual level). Sixth, the fact that two different sets of people provide the mindset metrics and the purchase data (which avoids mere measurement bias), could have introduced some noise in our analyses. Finally, while we focus on brand-level effects, future research can also examine the perspective of the retailer by using category-level metrics, e.g. category profits, as focal variables.

\section{Future Research}

In light of these limitations, the current study is only a first step in answering the call for more research on linking mindset metrics to performance in an integrated modeling framework (Marketing Science Institute 2006; Gupta and Zeithaml 2006). A first avenue for future research is to establish empirical generalizations by examining other mindset metrics, regions and product categories. Second, while our main finding on the explanatory power of mindset metrics holds up for different product categories and brands, future research should examine and quantify the extent to which the contribution of mindset metrics versus marketing mix varies across these categories and brands. Figure 4 illustrates such conditional analysis based on a median-split on brand expensiveness.

--- Insert Figure 4 about here ---

For expensive brands, the contribution of mind-set (marketing-mix) metrics is $17.6 \%$ $(30.8 \%)$ and the corresponding percentage for inexpensive brands is lower at $14.2 \%(41.9 \%)$. We speculate that expensive brands are likely to have higher levels of consumer involvement relative to inexpensive brands, which in turn corresponds to a greater role for the consumer's state of mind, as reflected in advertising awareness, consideration, and liking for such brands. Future research on a larger number of categories should explain cross-brand and cross-category variation in terms of, for instance, brand age, consumer involvement, product storability and competitive intensity. The impact of mindset metrics may also vary for different generic 
branding strategies (e.g., low-cost players versus innovators) and different phases of the product life cycle. In addition, future research may establish the continuing contribution of marketing actions to both baseline sales and deviations from this baseline.

Third, extensive qualitative data on marketing actions would allow future research to answer why mindset metrics matter in explaining sales. For instance, it is possible that advertising only increases bottled juice sales if a certain advertising message (e.g. healthy) resonates with an external consumer trend (e.g. toward health-promoting consumption). If the brand broadcasts a mix of such successful and less successful advertising messages over time, their sales effects will be averaged in a typical marketing mix model relating advertising quantity to sales. However, brand liking will only increase with the 'high-quality' advertising messages, and will thus add to the average advertising effect in our model explaining sales. The same reasoning applies to promotions, for which different executions may differ greatly in their effectiveness (e.g. to include the brand into the consideration set of new customers).

Fourth, our demonstration that mindset metrics lead sales does not imply that each possible mindset metric is worth measuring. We had to make a selection of three metrics, in discussion with the data provider, but mindset surveys usually collect a large set of metrics. Recent evidence shows that only a few of the sometimes hundreds of available metrics actually lead sales (Pauwels and Joshi 2008). Further research on metric selection is thus crucial.

A final important topic for future research is the chain of influence of marketing actions, over mindset effects, to sales performance. Although halo effects may exist among the mindset metrics (criticized for common method bias), we find that they each have a specific effect on sales and are influenced differently by marketing actions. The original hierarchy-of-effects models were criticized for imposing one unidirectional sequence. Instead, dual causality likely exists among mindset metrics, and between mindset metrics and marketing actions. For one, while consumers may like available brands more (distribution affects liking), retailers are also more likely to stock products liked by consumers (liking affects distribution). Our demonstration 
of the importance of mindset analysis should renew interest on the sequence of influence and how it differs across categories and brands. Growing this research stream would allow a metaanalysis to provide 'best guess' estimates for all links in the metric value chain, so that marketing effectiveness may be tracked within the conceptual framework of Figure 1, even in situations where specific information on a certain link is missing (Lehmann 2005).

In sum, we urge (1) quantitative modelers to open the 'black box' of customer mindset metrics, (2) branding experts to consider competition more explicitly when tracking mindset metrics and (3) both to pay more attention to the role of distribution as a driver of (even mature) brands. We hope our work thus contributes to the ongoing efforts of academic research to integrate behavioral with attitudinal data in market response models and to help managers demonstrate the importance of marketing actions in improving company performance. 
Figure 1: Framework - Marketing Actions, Customer Mindset Metrics and Brand Performance

(Adapted from Lehmann and Reibstein, 2006)

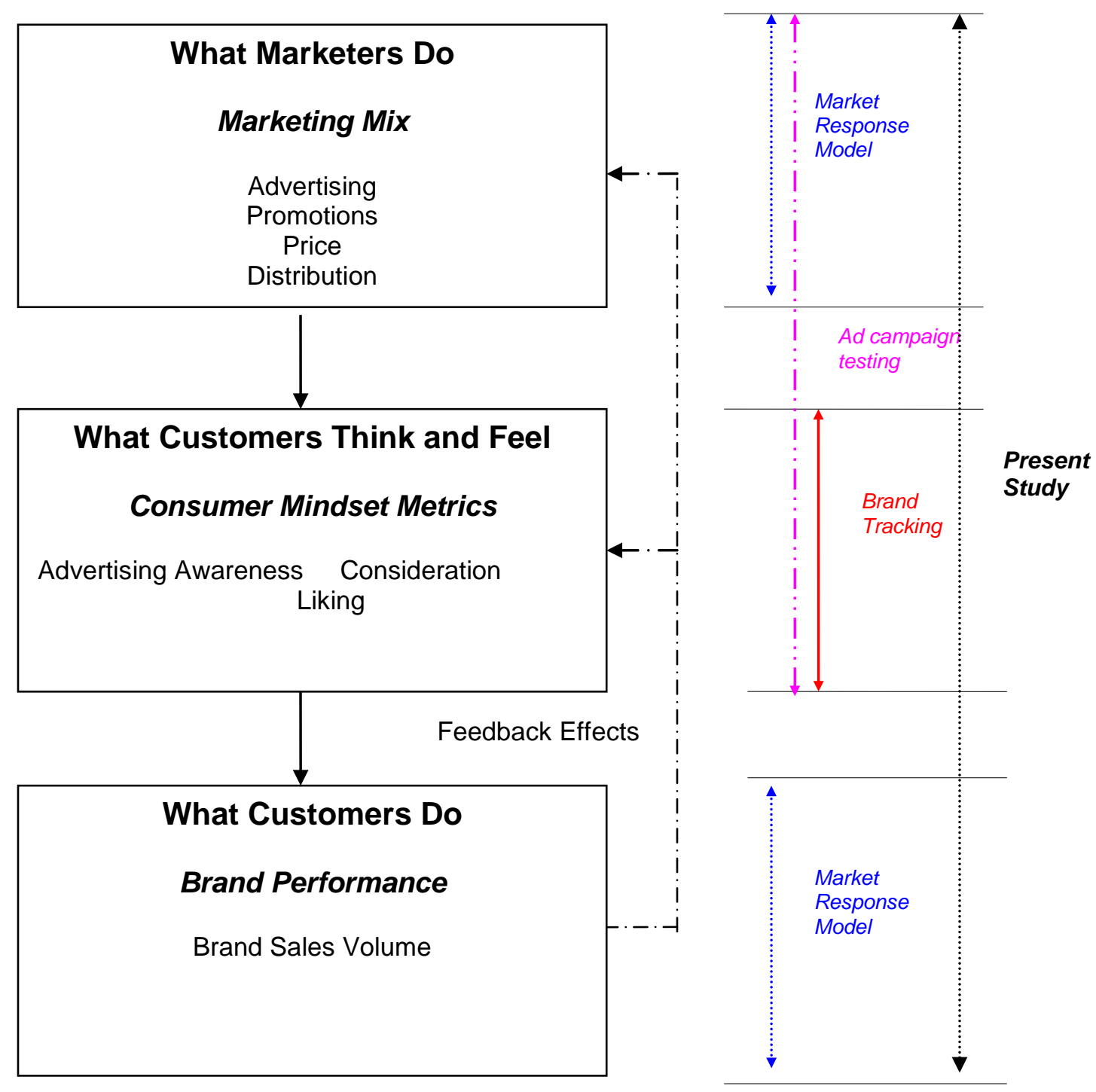


Figure 2: Mindset Metrics for Representative Brands*
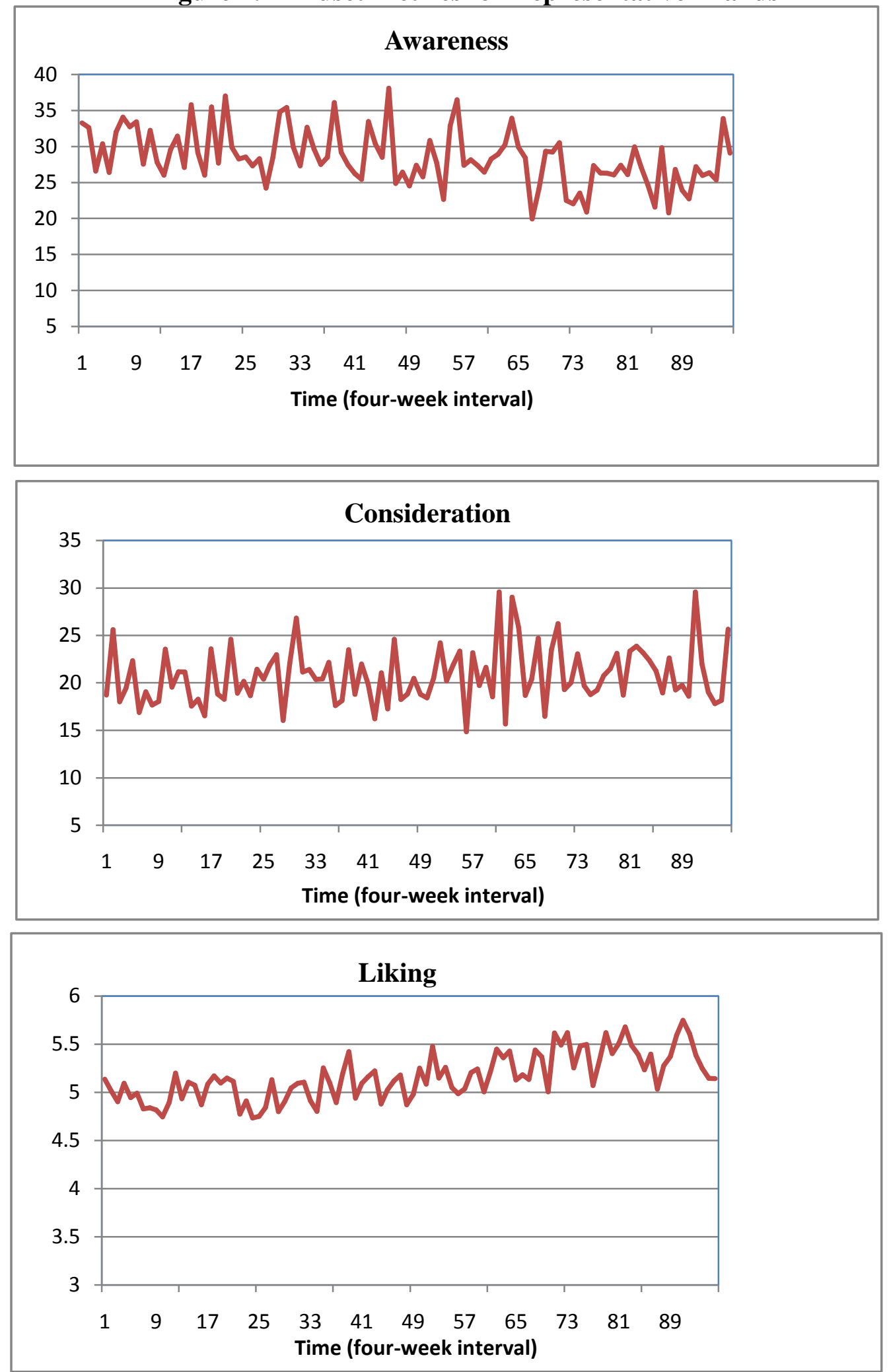

*For each mindset metric, we display the brand with the median variation on that metric. 
Figure 3: Comparison of R2 of the Benchmark Modelsvs.FullModel

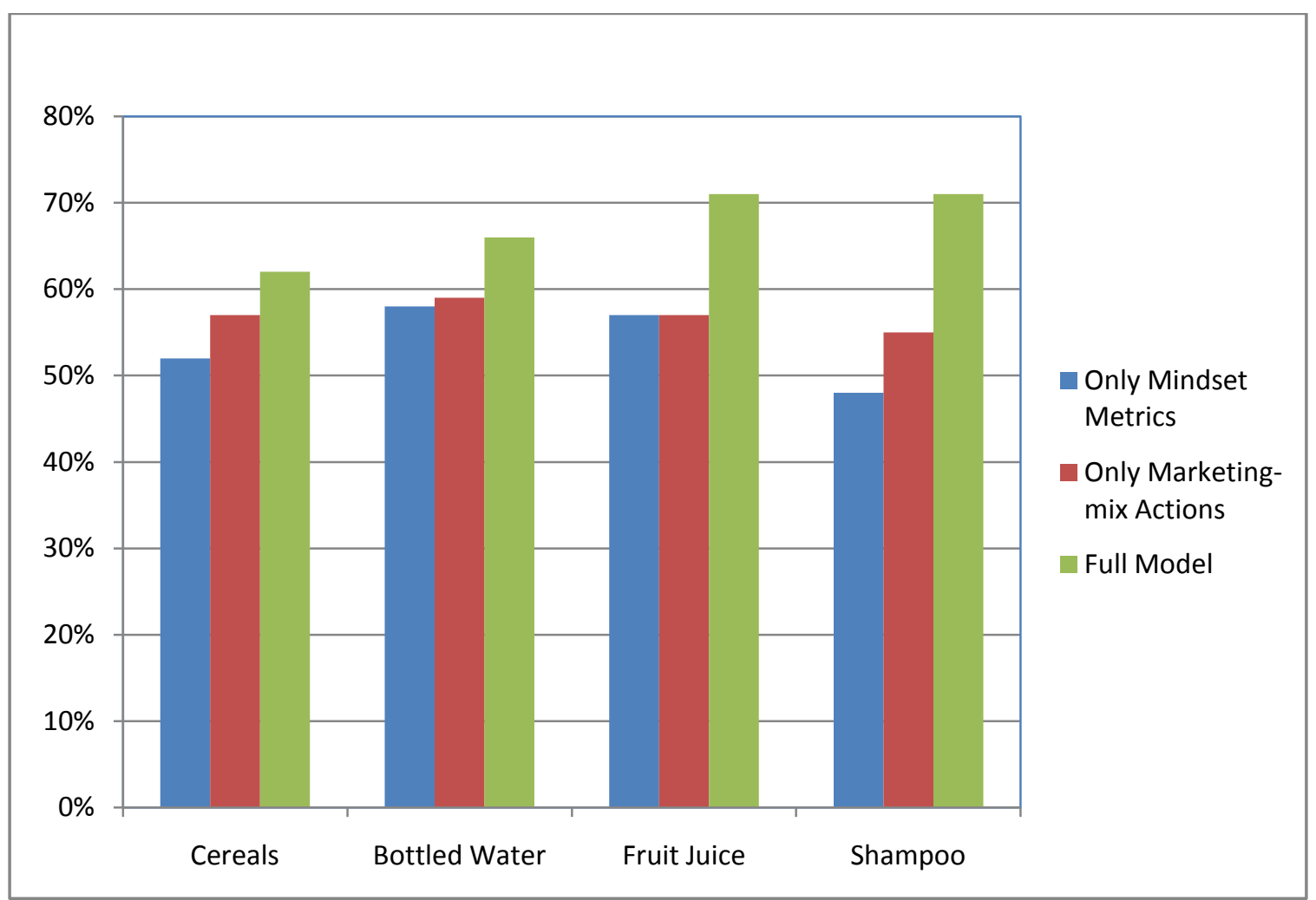


Figure 4: Brand Expensiveness and Variance Explained by Mindset Metrics and Marketing Mix Actions

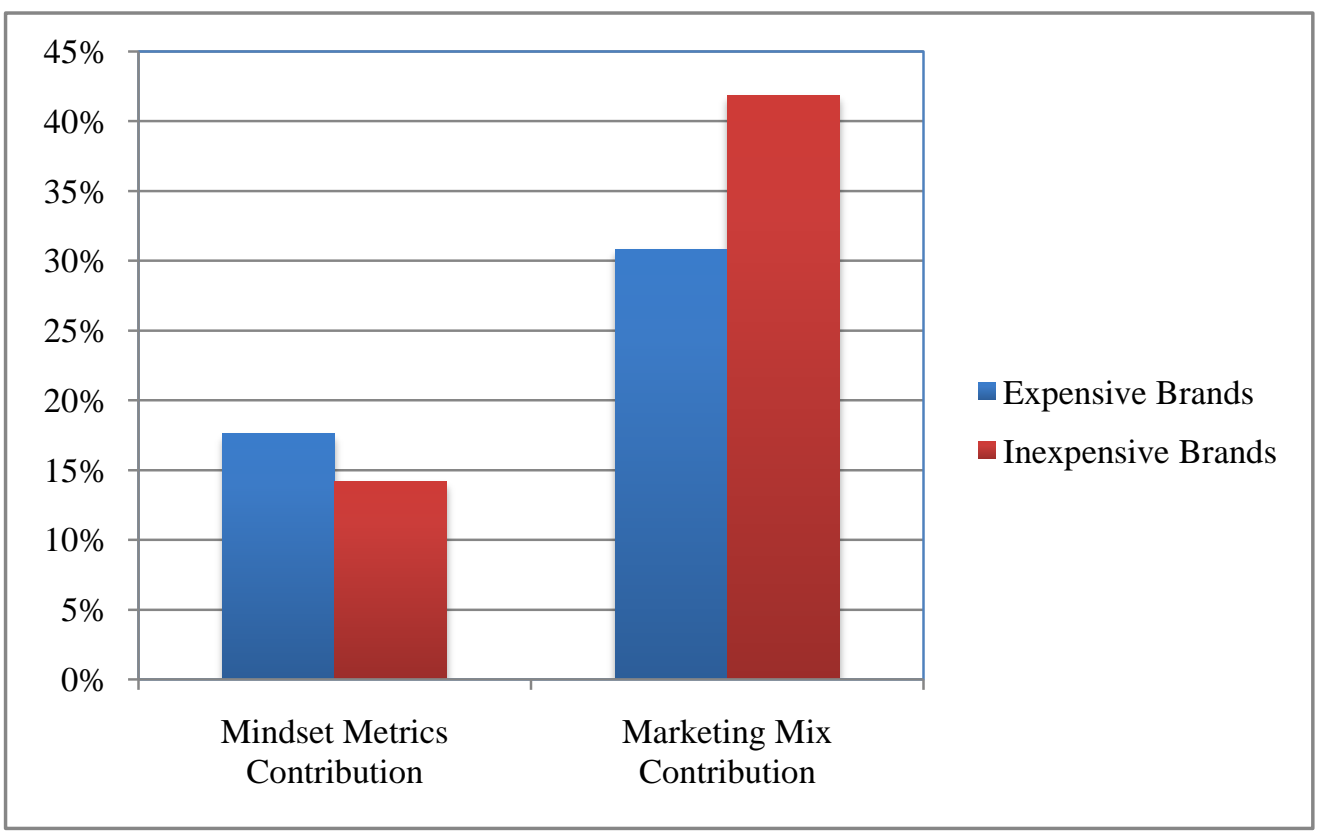


Table 1 Descriptive Statistics on Marketing Mix and Mind Metrics (Average Values for Four Weeks across all Brands with Intertemporal Standard Deviations in Parentheses)

\begin{tabular}{|l|c|c|c|c|}
\hline Variables & Cereals & Bottled water & Fruit juice & Shampoo \\
\hline $\begin{array}{l}\text { Distribution } \\
\text { (value-weighted \%) }\end{array}$ & $\begin{array}{c}95.0 \\
(18.5)\end{array}$ & $\begin{array}{c}91.2 \\
(8.0)\end{array}$ & $\begin{array}{c}79.6 \\
(13.1)\end{array}$ & $\begin{array}{c}92.4 \\
(15.6)\end{array}$ \\
\hline Promotions & 15.1 & 16.8 & 21.9 & 24.0 \\
(\% of volume on promotion) & $(3.7)$ & $(3.7)$ & $(2.8)$ & $(4.7)$ \\
\hline & & & & \\
Advertising & 251.6 & 402.1 & 121.9 & 359.0 \\
(in '000 euro) & $(179.5)$ & $(343.3)$ & $(119.1)$ & $(247.0)$ \\
\hline & 16.9 & 20.6 & 11.4 & 18.5 \\
Advertising Awareness & $(3.0)$ & $(1.5)$ & $(3.3)$ & $(3.1)$ \\
(\% aware) & & & & \\
\hline & 18.4 & 17.9 & 18.3 & 15.9 \\
Consideration & $(2.7)$ & $(0.8)$ & $(3.1)$ & $(2.3)$ \\
(\% considering buying) & & 5.3 & 5.6 & 4.6 \\
\hline $\begin{array}{l}\text { Liking } \\
\text { (scale value) }\end{array}$ & 5.1 & $(0.5)$ & $(0.8)$ & $(1.0)$ \\
\hline
\end{tabular}


Table 2: Overview of Analysis Steps

\begin{tabular}{|c|c|c|c|}
\hline Methodology & $\begin{array}{l}\text { Econometrics } \\
\text { literature }\end{array}$ & $\begin{array}{l}\text { Marketing } \\
\text { literature }\end{array}$ & Research questions \\
\hline $\begin{array}{l}\frac{1 \mathrm{~A} \text {. Unit root tests }}{\text { Augmented Dickey-Fuller }} \\
\text { Structural break test }\end{array}$ & $\begin{array}{l}\text { Enders (2004) } \\
\\
\text { Perron (1989) } \\
\text { Perron (1990) } \\
\text { Zivot and Andrews } \\
\text { (1992) }\end{array}$ & $\begin{array}{l}\text { Pauwels et al. } \\
\text { (2002) } \\
\text { Srinivasan et al. } \\
\text { (2000) }\end{array}$ & $\begin{array}{l}\text { Is each variable } \\
\text { (mean/trend) } \\
\text { stationary or evolving } \\
\text { (unit root)? } \\
\text { Is there a structural } \\
\text { break in the time } \\
\text { series of each } \\
\text { variable? }\end{array}$ \\
\hline $\begin{array}{l}\text { 1B. Vector Autoregressive } \\
\text { model with exogenous variables } \\
\text { (VARX) }\end{array}$ & Lütkepohl (1993) & $\begin{array}{l}\text { Dekimpe and } \\
\text { Hanssens (1995) } \\
\text { Nijs et al. (2001) }\end{array}$ & $\begin{array}{l}\text { How do key variables } \\
\text { interact, accounting } \\
\text { for exogenous factors? }\end{array}$ \\
\hline 2A. Variance decomposition & & & \\
\hline $\begin{array}{l}\text { Forecast error variance } \\
\text { decomposition } \\
\text { Generalized forecast error } \\
\text { variance decomposition } \\
\text { (GFEVD) }\end{array}$ & $\begin{array}{l}\text { Enders (2004) } \\
\text { Pesaran and Shin } \\
\text { (1998) }\end{array}$ & $\begin{array}{l}\text { Hanssens (1998) } \\
\text { Pauwels et al. } \\
\text { (2004) } \\
\text { Nijs, Srinivasan } \\
\text { and Pauwels (2007) }\end{array}$ & $\begin{array}{l}\text { Do mindset } \\
\text { metricsmatter in } \\
\text { explaining sales over } \\
\text { time...? } \\
\text {...without imposing a } \\
\text { causal ordering on the } \\
\text { variables? }\end{array}$ \\
\hline 2B. Impulse Response Functions & $\begin{array}{l}\text { Pesaran and Shin } \\
\text { (1998) }\end{array}$ & $\begin{array}{l}\text { Nijs et al. (2001) } \\
\text { Srinivasan et al. } \\
\text { (2004) }\end{array}$ & $\begin{array}{l}\text { What is the net } \\
\text { performance response } \\
\text { of a marketing } \\
\text { impulse? }\end{array}$ \\
\hline
\end{tabular}




\section{Table 3: Variance Explained by Dynamic Drivers of Brand Performance Based on GFEVD Analysis}

\begin{tabular}{|c|c|c|c|c|c|c|c|c|c|c|c|}
\hline \multirow[t]{3}{*}{ Response to } & \multicolumn{9}{|c|}{ Brand Sales Performance } & Share & Revenue \\
\hline & \multicolumn{3}{|c|}{ Mean } & \multicolumn{3}{|c|}{ Median } & \multicolumn{3}{|c|}{ Standard Deviation } & \multicolumn{2}{|l|}{ Mean } \\
\hline & BM1 & BM2 & FM & BM1 & BM2 & FM & BM1 & BM2 & FM & FM & FM \\
\hline \multicolumn{12}{|l|}{ Own... } \\
\hline Price & $8.7 \%$ & & $7.6 \%$ & $8.8 \%$ & & $7.5 \%$ & $8.9 \%$ & & $7.7 \%$ & $8.5 \%$ & $4.9 \%$ \\
\hline Promotion & $10.3 \%$ & & $7.5 \%$ & $10.2 \%$ & & $7.5 \%$ & $8.2 \%$ & & $6.5 \%$ & $8.0 \%$ & $7.8 \%$ \\
\hline Advertising & $4.6 \%$ & & $4.4 \%$ & $4.7 \%$ & & $4.3 \%$ & $5.1 \%$ & & $4.3 \%$ & $3.9 \%$ & $4.5 \%$ \\
\hline Distribution & $2.7 \%$ & & $3.6 \%$ & $2.8 \%$ & & $3.5 \%$ & $2.7 \%$ & & $3.1 \%$ & $3.8 \%$ & $3.4 \%$ \\
\hline $\begin{array}{l}\text { Own Marketing } \\
\text { Mix }\end{array}$ & $26.3 \%$ & & $23.1 \%$ & $26.5 \%$ & & $22.8 \%$ & $7.3 \%$ & & $5.9 \%$ & $24.2 \%$ & $20.6 \%$ \\
\hline \multicolumn{12}{|l|}{ Competitive... } \\
\hline Price & $3.2 \%$ & & $3.7 \%$ & $3.1 \%$ & & $3.7 \%$ & $2.9 \%$ & & $3.2 \%$ & $2.5 \%$ & $3.3 \%$ \\
\hline Promotion & $4.6 \%$ & & $4.0 \%$ & $4.6 \%$ & & $4.1 \%$ & $6.4 \%$ & & $5.0 \%$ & $4.2 \%$ & $4.1 \%$ \\
\hline Advertising & $3.4 \%$ & & $3.2 \%$ & $3.5 \%$ & & $3.1 \%$ & $2.6 \%$ & & $2.6 \%$ & $2.5 \%$ & $3.1 \%$ \\
\hline Distribution & $2.2 \%$ & & $2.9 \%$ & $2.3 \%$ & & $3.1 \%$ & $2.4 \%$ & & $3.2 \%$ & $3.5 \%$ & $2.8 \%$ \\
\hline $\begin{array}{l}\text { Competitive } \\
\text { Marketing Mix }\end{array}$ & $13.4 \%$ & & $13.8 \%$ & $13.5 \%$ & & $14.0 \%$ & $4.0 \%$ & & $3.6 \%$ & $12.7 \%$ & $13.3 \%$ \\
\hline \multicolumn{12}{|l|}{ Own... } \\
\hline Ad Awareness & & $7.8 \%$ & $3.4 \%$ & & $7.7 \%$ & $3.3 \%$ & & $8.8 \%$ & $3.2 \%$ & $3.3 \%$ & $3.3 \%$ \\
\hline Consideration & & $4.4 \%$ & $2.7 \%$ & & $4.6 \%$ & $2.6 \%$ & & $6.3 \%$ & $3.9 \%$ & $2.6 \%$ & $2.6 \%$ \\
\hline Liking & & $3.1 \%$ & $2.3 \%$ & & $3.2 \%$ & $2.4 \%$ & & $3.1 \%$ & $2.0 \%$ & $1.9 \%$ & $2.1 \%$ \\
\hline Own Mindset & & $15.3 \%$ & $8.4 \%$ & & $15.5 \%$ & $8.3 \%$ & & $6.8 \%$ & $3.2 \%$ & $7.8 \%$ & $8.0 \%$ \\
\hline \multicolumn{12}{|l|}{ Competitive... } \\
\hline Ad Awareness & & $4.2 \%$ & $2.6 \%$ & & $4.3 \%$ & $2.7 \%$ & & $4.4 \%$ & $2.5 \%$ & $2.9 \%$ & $3.4 \%$ \\
\hline Consideration & & $3.1 \%$ & $3.1 \%$ & & $3.2 \%$ & $3.2 \%$ & & $3.4 \%$ & $3.3 \%$ & $2.6 \%$ & $3.2 \%$ \\
\hline Liking & & $3.1 \%$ & $2.2 \%$ & & $3.0 \%$ & $2.3 \%$ & & $3.2 \%$ & $2.0 \%$ & $1.8 \%$ & $2.1 \%$ \\
\hline $\begin{array}{l}\text { Competitive } \\
\text { Mindset }\end{array}$ & & $10.4 \%$ & $7.9 \%$ & & $10.5 \%$ & $8.2 \%$ & & $3.7 \%$ & $2.7 \%$ & $7.3 \%$ & $8.7 \%$ \\
\hline Purchase Inertia & $60.3 \%$ & $74.3 \%$ & $46.8 \%$ & $60.0 \%$ & $74.0 \%$ & $46.7 \%$ & $12.3 \%$ & $12.2 \%$ & $12.6 \%$ & $48.0 \%$ & $49.4 \%$ \\
\hline
\end{tabular}

BM1 - Model with only Marketing Mix; BM2 - Model with only Mindset 
Table 4: Sales Elasticity to Marketing Mix and Mindset Metrics

\begin{tabular}{|c|c|c|c|}
\hline & Average Elasticity* & Median Elasticity* & $\begin{array}{c}\% \text { of Significant } \\
\text { Estimates } * *\end{array}$ \\
\hline \multicolumn{4}{|l|}{ Immediate Elasticity } \\
\hline \multicolumn{4}{|l|}{ Marketing mix } \\
\hline Price & -0.532 & -0.411 & $84 \%$ \\
\hline Promotion & 0.146 & 0.137 & $92 \%$ \\
\hline Advertising & 0.020 & 0.015 & $72 \%$ \\
\hline Distribution & 1.311 & 0.978 & $74 \%$ \\
\hline \multicolumn{3}{|l|}{ Total } & $81 \%$ \\
\hline \multicolumn{4}{|l|}{ Mindset } \\
\hline Advertising Awareness & 0.095 & 0.078 & $61 \%$ \\
\hline Consideration & 0.103 & 0.028 & $56 \%$ \\
\hline Liking & 0.222 & 0.174 & $59 \%$ \\
\hline \multicolumn{3}{|l|}{ Total } & $58 \%$ \\
\hline \multicolumn{4}{|l|}{ Cumulative Elasticity } \\
\hline \multicolumn{4}{|l|}{ Marketing mix } \\
\hline Price & -1.734 & -0.642 & $76 \%$ \\
\hline Promotion & 0.277 & 0.120 & $79 \%$ \\
\hline Advertising & 0.036 & 0.037 & $60 \%$ \\
\hline Distribution & 2.424 & 2.740 & $58 \%$ \\
\hline Total & & & $68 \%$ \\
\hline \multicolumn{4}{|l|}{ Mindset } \\
\hline Advertising Awareness & 0.289 & 0.149 & $58 \%$ \\
\hline Consideration & 0.374 & 0.093 & $56 \%$ \\
\hline Liking & 0.590 & 0.519 & $56 \%$ \\
\hline \multicolumn{3}{|l|}{ Total } & $57 \%$ \\
\hline
\end{tabular}

* including significant and insignificant estimates.

$* *: \mathrm{p}<0.05$

The figures in the table above are measured as follows:

\section{Marketing mix:}

Immediate and Cumulative brand sales volume elasticity in response to a shock to price, promotion, advertising, and distribution.

\section{Consumer mindset:}

Immediate and Cumulative brand sales volume elasticity in response to a shock to ad awareness, consideration, and liking. 
Table 5: Wear-in of the Lead Effects on Sales

\begin{tabular}{|l|c|}
\hline Response to & Mean time (in months) \\
\hline Marketing-mix & \\
\hline Price & 1.59 \\
\hline Promotion & 1.02 \\
\hline Advertising & 1.83 \\
\hline Distribution & 2.12 \\
\hline & \\
Consumer mindset & \\
\hline Advertising Awareness & 2.32 \\
\hline Consideration & 2.23 \\
\hline Liking & 2.00 \\
\hline
\end{tabular}


Table 6: Mindset Metrics Average (Median) Elasticity to Marketing Mix*

\begin{tabular}{|l|c|c|c|c|c|c|}
\hline $\begin{array}{l}\text { Impact on } \\
\text { Mindset Metric } \\
\text { of a Shock to... }\end{array}$ & \multicolumn{2}{|c|}{ Advertising Awareness } & \multicolumn{2}{c|}{ Consideration } & \multicolumn{2}{c|}{ Liking } \\
\cline { 2 - 7 } & Immediate & Cumulative & Immediate & Cumulative & Immediate & Cumulative \\
\hline Price & $\begin{array}{c}0.000 \\
(0.001)\end{array}$ & $\begin{array}{c}-0.020 \\
(-0.001)\end{array}$ & $\begin{array}{c}0.061 \\
(0.056)\end{array}$ & $\begin{array}{c}0.018 \\
(0.018)\end{array}$ & $\begin{array}{c}-0.049 \\
(-0.049)\end{array}$ & $\begin{array}{c}-0.277 \\
(-0.256)\end{array}$ \\
\hline Promotion & $\begin{array}{l}0.003 \\
(0.002)\end{array}$ & $\begin{array}{c}0.049 \\
(0.052)\end{array}$ & $\begin{array}{c}0.015 \\
(0.016)\end{array}$ & $\begin{array}{c}0.032 \\
(0.019)\end{array}$ & $\begin{array}{c}-0.026 \\
(-0.023)\end{array}$ & $\begin{array}{c}0.149 \\
(0.138)\end{array}$ \\
\hline Advertising & $\begin{array}{c}0.027 \\
(0.026)\end{array}$ & $\begin{array}{c}0.064 \\
(0.074)\end{array}$ & $\begin{array}{c}0.005 \\
(0.004)\end{array}$ & $\begin{array}{c}0.020 \\
(0.018)\end{array}$ & $\begin{array}{c}0.001 \\
(0.001)\end{array}$ & $\begin{array}{c}0.002 \\
(0.003)\end{array}$ \\
\hline Distribution & $\begin{array}{c}0.483 \\
(0.465)\end{array}$ & $\begin{array}{c}0.887 \\
(0.839)\end{array}$ & $\begin{array}{c}0.490 \\
(0.608)\end{array}$ & $\begin{array}{c}1.040 \\
(1.527)\end{array}$ & $\begin{array}{c}0.320 \\
(0.400)\end{array}$ & $\begin{array}{c}0.517 \\
(0.781)\end{array}$ \\
\hline
\end{tabular}

* including significant and insignificant estimates.

The figures in the table above are measured as follows:

\section{Mindset response:}

Immediate and Cumulative mindset metric (advertising awareness, consideration, liking) elasticity in response to a shock to price, promotion, advertising and distribution. 


\section{REFERENCES}

Ailawadi, Kusum L., Donald R. Lehmann, Scott A. Neslin (2001), "Market Response to a Major Policy Change in the Marketing Mix: Learning from Procter \& Gamble's Value Pricing Strategy,"Journal of Marketing, 65 (1), 44-61.

Alba, Joseph W., Wes Hutchinson, and John G. Lynch (1991), "Memory and Decision Making," In: H.J. Kassarjian and T.S. Robertson, Editors, Handbook of Consumer Theory and Research, Prentice Hall, Englewood Cliffs, NJ.

Ambler, Tim, (2003), Marketing and the Bottom Line (2nd edn.), FT Prentice Hall, London. Ataman, Berk, Harald J. van Heerde, and Carl F. Mela. (2008), "Building Brands," Marketing Science, 27 (6), 1036-1054.

Ataman, Berk, Harald J. van Heerde, and Carl F. Mela. (2009), "The Long-term Effect of Marketing Strategy on Brand Sales,” Working Paper, Duke University, http://faculty.fuqua.duke.edu/ mela/bio/workingpapers.html, accessed April 13, 2009

Batra, Rajeev and Wilfred Vanhonacker (1988), "Falsifying Laboratory Results Through Fields Tests: A Time-Series Methodology and Some Results," Journal of Business Research, 16 (June), 281-300.

Belch, George E. and Michael A. Belch (2004), Advertising and Promotion: An Integrated Marketing Communications Perspective, 6th ed. New York: McGraw-Hill, 2004. Benkwitz, Alexander, Helmut Lütkepohl, and Jürgen Wolters (2001), “Comparison of Bootstrap Confidence Intervals for Impulse Responses of German Monetary Systems," Macroeconomic Dynamics, 5, 81-100.

Bijmolt, Tammo H.A., Harald J. Van Heerde, and Rik G.M. Pieters (2005), "New Empirical Generalizations on the Determinants of Price Elasticity," Journal of Marketing Research, 42 (May), 141-56.

Blattberg, Robert C. and Scott A Neslin (1990), Sales Promotion Concepts, Methods, and Strategies, Prentice-Hall, Englewood Cliffs, NJ.

Boyd Harper W., Michael L. Ray, and Strong, Edward C. (1972), “An Attitudinal Framework for Advertising Strategy,” Journal of Marketing, 36 (April), 27-33 Bronnenberg Bart, Vijay Mahajan, and Wilfried Vanhonacker (2000), "The Emergence of Market Structure in New Repeat-Purchase Categories: A Dynamic Approach and an Empirical Application," Journal of Marketing Research, 37 (1), 16-31. 
Christen, Marcus, Sachin Gupta, John C. Porter, Richard Staelin and Dick R. Wittink (1997), "Using market-level data to understand non-linear promotion effects," Journal of Marketing Research, 34 (3), 322-34.

Colley, Russell H., (1961), Defining Advertising Goals for Measured Advertising Results, New York, Association of National Advertisers.

Davis, John (2006), Measuring Marketing: 103 Key Metrics Every Marketer Needs, Wiley.

Dekimpe, Marnik G. and Dominique M. Hanssens (1995), “The Persistence of Marketing Effects on Sales," Marketing Science 14 (1), 1-21.

Dekimpe, Marnik G. and Dominique M. Hanssens (1999), "Sustained Spending and Persistent Response: A New Look at Long-Term Marketing Profitability,” Journal of Marketing Research, 36 (November), 397-412.

Dekimpe, Marnik G. and Dominique M. Hanssens (2007), “Advertising Response Models,” inHandbook of Advertising, Gerald J. Tellis and Tim Ambler, Eds., Sage Publications.

Enders, Walter (2004), Applied Econometric Time Series, John Wiley, NY.

Evans, Lewis and Graeme Wells(1983), “An Alternative Approach to Simulating VAR Models," Economic Letters, 12 (1), 23-29.

Farris, Paul W., Neil T. Bendle, Phillip E. Pfeifer, and David J. Reibstein (2006), 50+ Metrics Every Executive Should Master, Wharton School Publishing, Philadelphia.

Franses, Philip Hans and Marco Vriens (2004), “Advertising Effects on Awareness, Consideration and Brand Choice Using Tracking Data," Working Paper, Erasmus University.

Gupta, Sunil and Valarie Zeithaml (2006), "Customer Metrics and their Impact on Financial Performance," Marketing Science, 25 (6), 718-739.

Hamilton, James (1994), Time Series Analysis. Princeton, N.J.: Princeton University Press.

Hanssens, Dominique M. (1998), "Order Forecasts, Retail Sales and the Marketing Mix for Consumer Durables," Journal of Forecasting, 17, 327-346.

Hanssens, Dominique M., Leonard J. Parsons, and Randall L. Schultz (2001), Market Response models: Econometric and Time Series Analysis. $2^{\text {nd }}$ edition, Kluwer Academic Publishers. 
Horváth, Csilla (2003), Dynamic Analysis of a Competitive Marketing System, Doctoral Dissertation, University of Groningen, The Netherlands.

Keller, Kevin Lane (2003), “Conceptualizing, Measuring, and Managing Customer-Based Brand Equity," Journal of Marketing, 57 (January), 1-22.

Keller, Kevin Lane and Donald R. Lehmann (2006), "Brands and Branding: Research Findings and Future Priorities,” Marketing Science, 25 (November-December), 740759.

Kotler, Philip (2003), Marketing Insights from A to Z: 80 Concepts Every Manager Needs to Know, John Wiley and Sons, Inc.

Kotler, Philip and Kevin Lane Keller (2006), Framework for Marketing Management, 3rd Edition, Pearson Education, Inc.

Lambin, Jean-Jacques (1976), Advertising, Competition and Market Conduct in Oligopoly over Time, Amsterdam, North Holland.

LaPointe, Patrick (2005), Marketing by the Dashboard Light, ANA Press.

Lehmann, Donald R. (2004), “Metrics for Making Marketing Matter," Journal of Marketing, (68), 73-75.

Lehmann, Donald R. (2005), “The Metrics Imperative: Making Marketing Matter,” Review of Marketing Research, 2, 177-202.

Lehmann, Donald R. and David J. Reibstein (2006), Marketing Metrics and Financial Performance, Marketing Science Institute, Cambridge, MA.

Little, John D.(1979), "Aggregate Advertising Models: The State of the Art," Operations Research, 27 (4), 629-667.

Lütkepohl, Helmut (1993), Introduction to Multiple Time Series Analysis, Springer-Verlag, Berlin.

Lütkepohl, Helmut and M. Krätzig (eds.). 2004. Applied Time Series Econometrics,Cambridge, UK, Cambridge University Press, NY.

Marketing Science Institute (2006), 2006-2008 Research Priorities: A Guide to MSI Research Programs and Procedures. Cambridge, Mass: Marketing Science Institute. Morwitz, Vicky G., Eric Johnson, and David Schmittlein (1993), "Does measuring intent change behavior?” Journal of Consumer Research, 20 (June), 41-61. 
Nijs, Vincent R., Marnik G. Dekimpe, Jan-Benedict E.M. Steenkamp, and Dominique M. Hanssens (2001), “The Category Demand Effects of Price Promotions,” Marketing Science, 20 (1), 1-22.

Nijs, Vincent R., Shuba Srinivasan, and Koen H. Pauwels (2007), "Retail-Price Drivers and Retailer Profits," Marketing Science, 26 (4), 473-487.

Palda, Kristian S. (1966), "The Hypothesis of a Hierarchy of Effects: A Partial Evaluation," Journal of Marketing Research, 3 (1), 13-24.

Pauwels, Koen H. (2004), "How Dynamic Consumer Response, Competitor Response, Company Support and Company Inertia Shape Long-term Marketing Effectiveness”, Marketing Science, 23 (4), 596-610

Pauwels, Koen H., Tim Ambler, Bruce Clark, Pat LaPointe, David Reibstein, Bernd Skiera, Berend Wierenga, and Thorsten Wiesel (2009), "Dashboards as a Service: why, what, how and what research is needed?" Journal of Service Research, November, forthcoming..

Pauwels, Koen H., Dominique M. Hanssens, and S. Siddarth (2002), “The Long-term Effects of Price Promotions on Category Incidence, Brand Choice, and Purchase Quantity," Journal of Marketing Research, 34 (November) 421-439.

Pauwels, Koen H. and Dominique M. Hanssens (2007), “Performance Regimes and Marketing Policy Shifts," Marketing Science, 26 (3), 293-311

Pauwels, Koen H. and Amit Joshi (2008), “Counting What Will Count: Does Your Dashboard Predict?” Working Paper, Tuck School of Business at Dartmouth, Hanover, NH.

Pauwels, Koen H., Jorge M. Silva-Risso, Shuba Srinivasan, and Dominique M. Hanssens (2004), "New Products, Sales Promotions and Firm Value, With Application to the Automobile Industry," Journal of Marketing, 68(October), 142-156.

Pauwels, Koen H. and Shuba Srinivasan (2004), “Who Benefits From Store Brand Entry?” Marketing Science, 23 (3), 364-390.

Perron, Pierre (1989), "The Great Crash, the Oil Price Shock and the Unit Root Hypothesis," Econometrica,57 (6), 1361-1401.

Perron, Pierre (1990), "Testing for a Unit Root in a Time Series with a Changing Mean," Journal of Business and Economic Statistics, 8 (2), 153-162. 
Pesaran, Hashem H. and Yongcheol Shin (1998), "Generalized Impulse Response Analysis in Linear Multivariate Models," Economic Letters, 58 (1), 17-29.

Rust, Roland T., Tim Ambler, Gregory S. Carpenter, V. Kumar, and Rajendra K. Srivastava (2004), "Measuring Marketing Productivity: Current Knowledge and Future Directions," Journal of Marketing, 68 (4), 76-89.

Slotegraaf, Rebecca J. and Koen H. Pauwels (2008), “The Impact of Brand Equity and Innovation on the Long-term Effectiveness of Promotions," Journal of Marketing Research, 45(3), 293-306.

Srinivasan, Shuba and Dominique M. Hanssens (2009), "Marketing and Firm Value: Metrics, Methods, Findings, and Future Directions," Journal of Marketing Research, forthcoming.

Srinivasan, Shuba, Peter T.L. Popkowski, and Frank M. Bass (2000), "Market share response and competitive interaction: The impact of temporary, evolving and structural changes in prices," International Journal of Research in Marketing, 17 (4), 281-305.

Srinivasan, Shuba, Koen H. Pauwels, Dominique M. Hanssens, and Marnik G. Dekimpe (2004), “Do Promotions Benefit Manufacturers, Retailers or Both?” Management Science, 50 (5), 617-629.

Srinivasan, Shuba, Koen H. Pauwels, and Vincent Nijs (2008), "Demand-Based Pricing Versus Past-Price Dependence: A Cost-Benefit Analysis,” Journal of Marketing, $72(2), 15-27$.

Tellis, Gerard J. (1988), “The Price Elasticity of Selective Demand: a Meta-Analysis of Econometric Models of Sales," Journal of Marketing Research, 15 (3), 331-41.

Tellis, Gerard J. (2004), Effective Advertising: Understanding When, How, and Why Advertising Works, Thousand Oaks: Sage Publications.

Tellis, Gerard J. and Tim Ambler (2007), Handbook of Advertising, London, UK: Sage Publications.

Van Heerde, Harald J., Peter S. H. Leeflang, and Dick R. Wittink (2004), "Decomposing the Sales Promotion Bump with Store Data,” Marketing Science, 23 (3), 317-334.

Van Heerde, Harald J., Shuba Srinivasan and Marnik G. Dekimpe (2008), "Decomposing the Demand for a Pioneering Innovation," Working Paper, University of California, Riverside. 
Vakratsas, Demetrios and Ambler, Tim (1999), "How Advertising Works: What Do We Really Know?” Journal of Marketing, 36 (1), 26-43.

Webster, Fredrick, Alan Malter, and Shankar Ganesan (2003), "Can Marketing Regain its Seat at the Table," MSI Reports, Issue 3, 29-48.

Zinkhan, George M. and Claes Fornell (1989), “A Test of the Learning Hierarchy in HighLow-Involvement Situations" Advances in Consumer Research, Provo, Utah: Association for Consumer Research, 16, 152-159.

Zivot, Eric, and Donald W. K.Andrews (1992), "Further Evidence on the Great Crash, the Oil-Price Shock, and the Unit-Root Hypothesis”,Journal of Business \& Economic Statistics, 10 (3), 251-270.

Zufryden, Fred (1996), "Linking Advertising to Box-Office Performance of New Film Releases - A Marketing Planning Model," Journal of Advertising Research, 36 (4), $29-41$. 


\section{Web-based TechnicalAppendix A - VARX Specification}

Specification of VARX Model

We estimate a 15-equation VARX model per brand, where the endogenous variables are sales $(S)$, the three mindset variables of advertising awareness $(A W A)$, brand liking $(L I K)$, brand consideration $(C O N S)$, the four marketing mix variables of average retail price $(P R I)$, promotion $(P R O)$, advertising $(A D V)$, distribution $(D I S)$ and the seven corresponding competitive variables, prefixed with $(C)$ to denote competition. In full notation the model given is by,

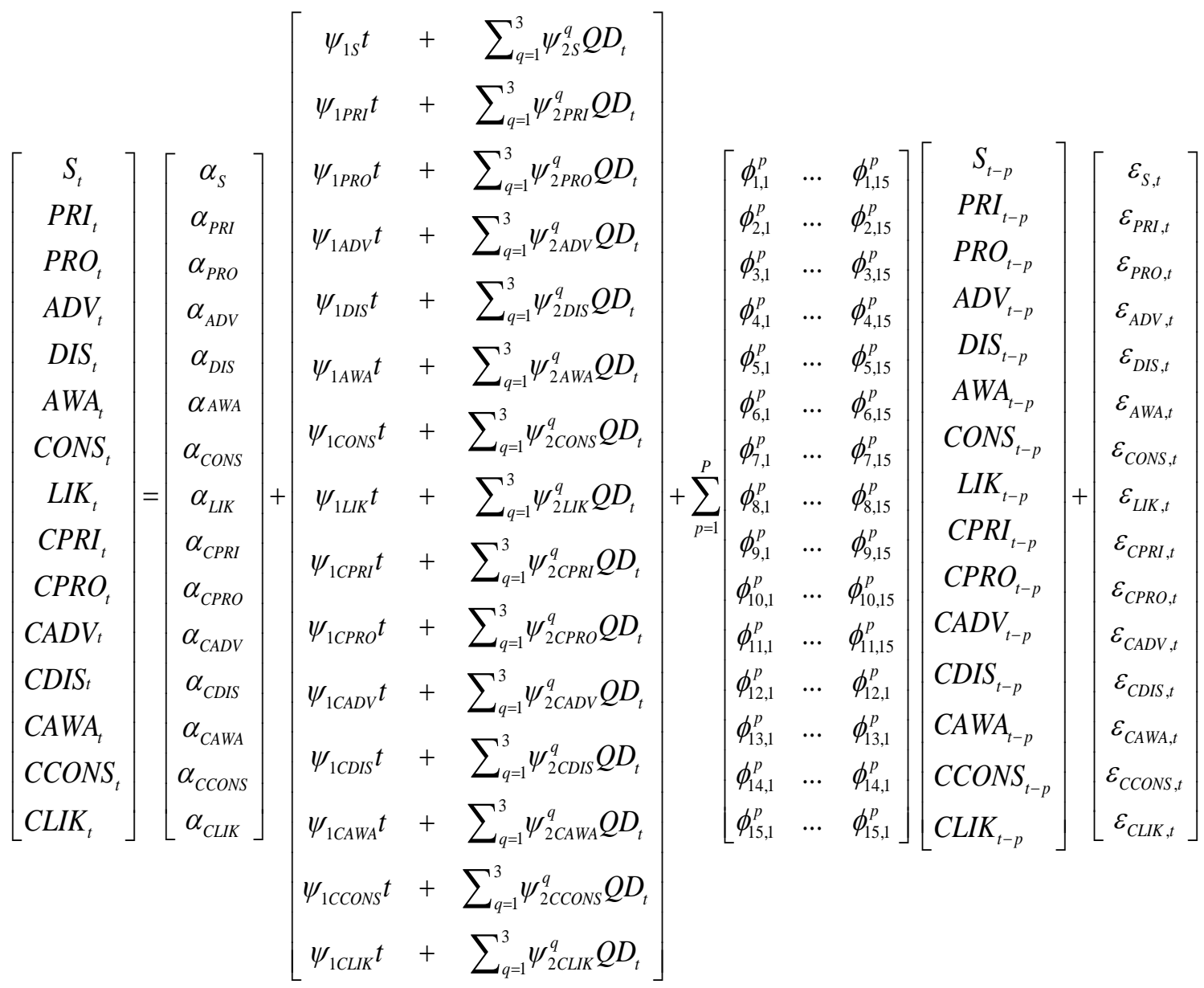

where $t$ isthe deterministic-trend and the quarterly dummy variables are denoted by $Q D$.

$\Sigma$ is the covariance matrix of the residuals $\left[\varepsilon_{S, t} \varepsilon_{P R I, t} \varepsilon_{P R O, t} \varepsilon_{A D V, t} \varepsilon_{D I S, t} \varepsilon_{A W A, t} \varepsilon_{C O N S, t} \varepsilon_{L I K, t} \varepsilon_{C P R I, t}\right.$ $\left.\varepsilon_{C P R O, t} \varepsilon_{C A D V, t} \varepsilon_{C D I S, t} \varepsilon_{C A W A, t} \varepsilon_{C C O N S, t} \varepsilon_{C L I K, t}\right]^{\prime}$. The dynamic interactions and feedback effects 
in Figure 1 are captured in the above VARX model (Dekimpe and Hanssens 2007). For instance, past sales gains (which imply more consumer experience with the brand in the market) influence current levels of consumer mindset metrics through coefficients $\varphi_{6,1}^{p_{6}}$ $\varphi_{8,1}^{\mathrm{p}_{8}}$. Likewise, past sales may influence company advertising through coefficient $\varphi_{4,1}^{\mathrm{p}}$.

As benchmark models, we estimate (a) the 9-equation benchmark VARX model obtained by deleting the six mindset metric equations from the full VARX model and (b) the 7-equation VARX model obtained by deleting the eight marketing-mix equations from the full VARX model. For the model (a), a 9-equation VARX model was estimated where the endogenous variables are sales, the four marketing mix variables - average retail price, advertising, distribution, promotion and the four corresponding competitive marketing-mix variables. In matrix notation the model given is by,

$$
Y_{1 t}=A_{1}+\sum_{i=1}^{p} \phi_{1 i} Y_{1 t-i}+\psi_{1} X_{1 t}+\Sigma_{1 t}, \quad t=1,2, \ldots ., T
$$

where $A_{l}$ is a $9 \times 1$ vector of intercepts, $Y_{l t}$ is an $9 \times 1$ vector of the endogenous variables listed above, and $X_{I t}$ is a vector of exogenous control variables: (a) a deterministic-trend $\mathrm{t}$ to capture the impact of omitted, gradually-changing variables, and (b) quarterly dummy variables to account for seasonal fluctuations in sales or any other endogenous variable. $\Sigma_{l t}$ is the covariance matrix of the residuals. A similar specification is used for the second benchmark model given by,

$$
Y_{2 t}=A_{2}+\sum_{i=1}^{p} \phi_{2 i} Y_{2 t-i}+\psi_{2} X_{2 t}+\Sigma_{2 t}, \quad t=1,2, \ldots ., T
$$

where $A_{2}$ is a $7 \times 1$ vector of intercepts, $Y_{2 t}$ is the vector of 7 endogenous variables includes brand sales, the three mindset metrics variables, advertising awareness, consideration, liking and the three corresponding competitive mindset metrics variables. $X_{2 t}$ is a vector of exogenous control variables and $\Sigma_{2 t}$ is the covariance matrix of the residuals.

The number of parameters per equation for the benchmark model (BM1) with only marketing mix variables is 14 for number of lags $(p)=1$. This includes lagged 
endogenous variables (9), intercept (1), deterministic trend (1), and quarterly dummies (3). The number of parameters per equation for $\mathrm{p}=2$, for example, is 23 , including 9 additional parameters for the lags. For the model with mindset metrics only (BM2), the number of parameters per equation is 12 for $\mathrm{p}=1$ and 19 for $\mathrm{p}=2$. The corresponding numbers for the full model in equation (1) in the main text are 20 per equation for $\mathrm{p}=1$. This includes lagged endogenous variables (15), intercept (1), deterministic trend (1), and quarterly dummies (3) and the corresponding number is 35 for $\mathrm{p}=2$ (including 15 parameters for lags). The VARX models are estimated equation by equation (OLS is as efficient as SUR since the independent variables are identical across each equation). Therefore, a VARX model of order 1 (i.e. $\mathrm{p}=1$ ) estimates 20 parameters from 96 observations (a 4.8 observation-to-parameter ratio), while a model of order 2 estimates 35 parameters from 96 observations (a 2.7 ratio) etc. In the vast majority of cases, 1 lag was selected using the SBC criterion; the remaining models used 2 lags. As a result, the overall observation-to-parameter ratio is 4.2 .

Finally, the VARX parameters from each of the models, the full model and the two benchmark models, are then used to derive GFEVD estimates (Pesaran and Shin 1998). To evaluate the accuracy of our GFEVD estimates, we obtain standard errors using Monte Carlo simulations (see Benkwitz et al. 2001).

\section{Brand-specific results: explanatory power and sales elasticity estimates}

Tables A1-A3 present the brand-specific results on explanatory power of both benchmark models and the full model. Table A4 presents the brand specific results on the sales elasticities for the own marketing actions and mindset metrics. 
Table A1: $\quad R^{2}$ for the Benchmark Model with only marketing actions

\begin{tabular}{|c|c|c|c|c|c|c|c|c|c|}
\hline \multirow[t]{2}{*}{ Brand } & \multicolumn{2}{|c|}{ Distribution } & \multicolumn{2}{|c|}{ Promotion } & \multicolumn{2}{|c|}{ Price } & \multicolumn{2}{|c|}{ Advertising } & \multirow{2}{*}{\begin{tabular}{|l} 
Volume \\
Own
\end{tabular}} \\
\hline & $\mathrm{O}$ & $\mathrm{C}$ & $\mathrm{O}$ & $\mathrm{C}$ & $\mathrm{O}$ & $\mathrm{C}$ & $\mathrm{O}$ & $\mathrm{C}$ & \\
\hline$\# 1$ & 0.87 & 0.38 & 0.66 & 0.57 & 0.40 & 0.27 & 0.28 & 0.55 & 0.53 \\
\hline$\# 2$ & 0.24 & 0.34 & 0.41 & 0.59 & 0.49 & 0.33 & 0.27 & 0.53 & 0.20 \\
\hline$\# 3$ & 0.43 & 0.32 & 0.29 & 0.50 & 0.68 & 0.55 & 0.39 & 0.35 & 0.63 \\
\hline \# 4 & 0.19 & 0.27 & 0.21 & 0.49 & 0.47 & 0.42 & 0.25 & 0.33 & 0.42 \\
\hline$\# 5$ & 0.13 & 0.33 & 0.05 & 0.67 & 0.27 & 0.48 & 0.35 & 0.59 & 0.89 \\
\hline \#6 & 0.10 & 0.42 & 0.49 & 0.51 & 0.36 & 0.48 & 0.22 & 0.46 & 0.47 \\
\hline \# 7 & 0.92 & 0.40 & 0.53 & 0.65 & 0.43 & 0.10 & 0.21 & 0.51 & 0.43 \\
\hline$\# 8$ & 0.31 & 0.28 & 0.50 & 0.62 & 0.64 & 0.31 & 0.29 & 0.55 & 0.10 \\
\hline \#9 & 0.77 & 0.62 & 0.60 & 0.62 & 0.77 & 0.24 & 0.35 & 0.50 & 0.86 \\
\hline \# 10 & 0.95 & 0.46 & 0.62 & 0.36 & 0.59 & 0.14 & 0.35 & 0.45 & 0.28 \\
\hline \# 11 & 0.38 & 0.54 & 0.22 & 0.64 & 0.44 & 0.05 & 0.11 & 0.55 & 0.81 \\
\hline \# 12 & 0.61 & 0.43 & 0.62 & 0.52 & 0.61 & 0.11 & 0.42 & 0.52 & 0.92 \\
\hline \#13 & 0.61 & 0.49 & 0.29 & 0.61 & 0.70 & 0.14 & 0.14 & 0.56 & 0.88 \\
\hline \# 14 & 0.64 & 0.40 & 0.57 & 0.48 & 0.37 & 0.46 & 0.29 & 0.32 & 0.76 \\
\hline \# 15 & 0.37 & 0.50 & 0.56 & 0.62 & 0.53 & 0.08 & 0.36 & 0.55 & 0.71 \\
\hline \# 16 & 0.23 & 0.47 & 0.47 & 0.59 & 0.59 & 0.21 & 0.16 & 0.56 & 0.69 \\
\hline \# 17 & 0.34 & 0.38 & 0.42 & 0.58 & 0.32 & 0.28 & 0.34 & 0.53 & 0.38 \\
\hline \# 18 & 0.62 & 0.57 & 0.47 & 0.63 & 0.81 & 0.21 & 0.45 & 0.36 & 0.40 \\
\hline$\# 19$ & 0.52 & 0.74 & 0.58 & 0.73 & 0.69 & 0.60 & 0.71 & 0.24 & 0.56 \\
\hline \# 20 & 0.55 & 0.47 & 0.25 & 0.48 & 0.67 & 0.27 & 0.18 & 0.23 & 0.93 \\
\hline$\# 21$ & 0.18 & 0.69 & 0.36 & 0.63 & 0.26 & 0.18 & 0.27 & 0.21 & 0.66 \\
\hline$\# 22$ & 0.05 & 0.70 & 0.30 & 0.66 & 0.72 & 0.28 & 0.12 & 0.35 & 0.87 \\
\hline$\# 23$ & 0.97 & 0.37 & 0.12 & 0.61 & 0.64 & 0.17 & 0.10 & 0.23 & 0.74 \\
\hline$\# 24$ & 0.13 & 0.59 & 0.46 & 0.57 & 0.05 & 0.25 & 0.13 & 0.49 & 0.39 \\
\hline$\# 25$ & 0.08 & 0.41 & 0.36 & 0.59 & 0.54 & 0.18 & 0.36 & 0.38 & 0.39 \\
\hline$\# 26$ & 0.13 & 0.48 & 0.40 & 0.60 & 0.42 & 0.18 & 0.31 & 0.36 & 0.41 \\
\hline \# 27 & 0.18 & 0.29 & 0.19 & 0.66 & 0.69 & 0.19 & 0.27 & 0.49 & 0.47 \\
\hline$\# 28$ & 0.10 & 0.46 & 0.34 & 0.60 & 0.47 & 0.25 & 0.39 & 0.27 & 0.66 \\
\hline$\# 29$ & 0.15 & 0.31 & 0.16 & 0.63 & 0.66 & 0.16 & 0.20 & 0.43 & 0.31 \\
\hline$\# 30$ & 0.99 & 0.28 & 0.58 & 0.55 & 0.56 & 0.26 & 0.39 & 0.21 & 0.75 \\
\hline$\# 31$ & 0.16 & 0.35 & 0.28 & 0.60 & 0.42 & 0.18 & 0.10 & 0.21 & 0.68 \\
\hline$\# 32$ & 0.12 & 0.42 & 0.53 & 0.60 & 0.70 & 0.23 & 0.11 & 0.20 & 0.44 \\
\hline$\# 33$ & 0.08 & 0.42 & 0.30 & 0.63 & 0.52 & 0.26 & 0.21 & 0.23 & 0.44 \\
\hline$\# 34$ & 0.46 & 0.41 & 0.32 & 0.62 & 0.62 & 0.20 & 0.33 & 0.32 & 0.80 \\
\hline$\# 35$ & 0.08 & 0.35 & 0.47 & 0.59 & 0.77 & 0.40 & 0.18 & 0.39 & 0.62 \\
\hline$\# 36$ & 0.43 & 0.38 & 0.56 & 0.57 & 0.61 & 0.95 & 0.18 & 0.46 & 0.49 \\
\hline$\# 37$ & 0.98 & 0.04 & 0.29 & 0.41 & 0.34 & 0.41 & 0.31 & 0.45 & 0.24 \\
\hline$\# 38$ & 0.36 & 0.32 & 0.28 & 0.44 & 0.61 & 0.38 & 0.52 & 0.08 & 0.41 \\
\hline \# 39 & 0.36 & 0.15 & 0.51 & 0.40 & 0.52 & 0.37 & 0.28 & 0.38 & 0.54 \\
\hline$\# 40$ & 0.39 & 0.51 & 0.43 & 0.39 & 0.54 & 0.29 & 0.24 & 0.37 & 0.35 \\
\hline$\# 41$ & 0.37 & 0.45 & 0.46 & 0.40 & 0.81 & 0.49 & 0.46 & 0.39 & 0.48 \\
\hline$\# 42$ & 0.87 & 0.47 & 0.41 & 0.40 & 0.54 & 0.31 & 0.46 & 0.34 & 0.84 \\
\hline$\# 43$ & 0.83 & 0.40 & 0.42 & 0.39 & 0.66 & 0.33 & 0.35 & 0.35 & 0.86 \\
\hline$\# 44$ & 0.38 & 0.32 & 0.52 & 0.33 & 0.30 & 0.37 & 0.30 & 0.46 & 0.68 \\
\hline$\# 45$ & 0.43 & 0.40 & 0.46 & 0.38 & 0.62 & 0.39 & 0.34 & 0.39 & 0.70 \\
\hline$\# 46$ & 0.58 & 0.37 & 0.56 & 0.39 & 0.40 & 0.33 & 0.31 & 0.36 & 0.64 \\
\hline$\# 47$ & 0.55 & 0.47 & 0.51 & 0.40 & 0.57 & 0.32 & 0.39 & 0.46 & 0.33 \\
\hline$\# 48$ & 0.42 & 0.42 & 0.47 & 0.51 & 0.23 & 0.43 & 0.41 & 0.35 & 0.61 \\
\hline$\# 49$ & 0.83 & 0.46 & 0.55 & 0.62 & 0.64 & 0.46 & 0.40 & 0.30 & 0.69 \\
\hline$\# 50$ & 0.46 & 0.47 & 0.59 & 0.45 & 0.36 & 0.32 & 0.28 & 0.41 & 0.76 \\
\hline$\# 51$ & 0.43 & 0.46 & 0.59 & 0.59 & 0.91 & 0.39 & 0.47 & 0.36 & 0.48 \\
\hline$\# 52$ & 0.47 & 0.38 & 0.39 & 0.52 & 0.45 & 0.42 & 0.47 & 0.48 & 0.71 \\
\hline$\# 53$ & 0.94 & 0.46 & 0.51 & 0.55 & 0.64 & 0.42 & 0.39 & 0.37 & 0.43 \\
\hline \# 54 & 0.40 & 0.56 & 0.70 & 0.55 & 0.54 & 0.49 & 0.44 & 0.43 & 0.54 \\
\hline$\# 55$ & 0.90 & 0.41 & 0.40 & 0.53 & 0.67 & 0.38 & 0.50 & 0.26 & 0.61 \\
\hline$\# 56$ & 0.42 & 0.38 & 0.48 & 0.51 & 0.53 & 0.38 & 0.26 & 0.44 & 0.52 \\
\hline \# 57 & 0.72 & 0.40 & 0.74 & 0.65 & 0.82 & 0.39 & 0.21 & 0.51 & 0.32 \\
\hline \# 58 & 0.98 & 0.53 & 0.51 & 0.58 & 0.40 & 0.41 & 0.43 & 0.41 & 0.53 \\
\hline \# 59 & 0.45 & 0.08 & 0.54 & 0.45 & 0.26 & 0.38 & 0.33 & 0.31 & 0.58 \\
\hline$\# 60$ & 0.43 & 0.50 & 0.50 & 0.52 & 0.30 & 0.47 & 0.48 & 0.41 & 0.73 \\
\hline \#61 & 0.52 & 0.37 & 0.27 & 0.55 & 0.31 & 0.48 & 0.20 & 0.47 & 0.32 \\
\hline \# 62 & 0.60 & 0.56 & 0.52 & 0.48 & 0.61 & 0.32 & 0.39 & 0.31 & 0.70 \\
\hline Average & 0.43 & 0.41 & 0.47 & 0.57 & 0.54 & 0.32 & 0.31 & 0.39 & 0.57 \\
\hline
\end{tabular}

$\mathrm{O}=$ own effects equation; $\mathrm{C}=$ competitive effects equation; Average for the system $=$ Average of $\mathrm{R}^{2}$ from last row $=0.45$; and average $\mathrm{R}^{2}$ for the sales equation in the full model $=0.57$. 
Table A2: $\quad R^{2}$ for the Benchmark Model with only mindset metrics

\begin{tabular}{|c|c|c|c|c|c|c|c|}
\hline Brand & \multicolumn{2}{|c|}{ Awareness } & \multicolumn{2}{|c|}{ Consideration } & \multicolumn{2}{|c|}{ Liking } & \multirow{2}{*}{$\begin{array}{l}\text { Volume } \\
\text { Own }\end{array}$} \\
\hline & $\mathbf{O}$ & $\mathrm{C}$ & $\mathbf{O}$ & C & $\mathbf{O}$ & C & \\
\hline \# 1 & 0.46 & 0.16 & 0.20 & 0.48 & 0.32 & 0.60 & 0.37 \\
\hline$\# 2$ & 0.15 & 0.15 & 0.23 & 0.69 & 0.33 & 0.73 & 0.37 \\
\hline \#3 & 0.39 & 0.18 & 0.25 & 0.11 & 0.45 & 0.09 & 0.67 \\
\hline$\# 4$ & 0.16 & 0.20 & 0.29 & 0.45 & 0.24 & 0.12 & 0.41 \\
\hline$\# 5$ & 0.37 & 0.29 & 0.16 & 0.47 & 0.33 & 0.61 & 0.41 \\
\hline \# 6 & 0.13 & 0.10 & 0.28 & 0.43 & 0.32 & 0.12 & 0.54 \\
\hline \#7 & 0.22 & 0.20 & 0.20 & 0.48 & 0.36 & 0.54 & 0.56 \\
\hline \#8 & 0.74 & 0.70 & 0.59 & 0.53 & 0.36 & 0.68 & 0.62 \\
\hline$\# 9$ & 0.24 & 0.36 & 0.26 & 0.57 & 0.32 & 0.68 & 0.78 \\
\hline$\# 10$ & 0.20 & 0.20 & 0.19 & 0.37 & 0.42 & 0.59 & 0.41 \\
\hline \# 11 & 0.16 & 0.24 & 0.28 & 0.54 & 0.35 & 0.70 & 0.43 \\
\hline$\# 12$ & 0.27 & 0.12 & 0.21 & 0.32 & 0.38 & 0.61 & 0.59 \\
\hline \#13 & 0.23 & 0.21 & 0.25 & 0.46 & 0.35 & 0.60 & 0.71 \\
\hline \#14 & 0.33 & 0.41 & 0.31 & 0.26 & 0.51 & 0.16 & 0.43 \\
\hline \#15 & 0.18 & 0.23 & 0.28 & 0.51 & 0.35 & 0.64 & 0.51 \\
\hline \#16 & 0.19 & 0.24 & 0.27 & 0.56 & 0.30 & 0.66 & 0.45 \\
\hline \# 17 & 0.30 & 0.24 & 0.22 & 0.50 & 0.35 & 0.61 & 0.27 \\
\hline \# 18 & 0.25 & 0.72 & 0.33 & 0.16 & 0.44 & 0.62 & 0.86 \\
\hline \# 19 & 0.68 & 0.57 & 0.22 & 0.43 & 0.69 & 0.72 & 0.49 \\
\hline$\# 20$ & 0.48 & 0.21 & 0.28 & 0.33 & 0.23 & 0.10 & 0.64 \\
\hline \#21 & 0.67 & 0.23 & 0.16 & 0.31 & 0.18 & 0.14 & 0.51 \\
\hline$\# 22$ & 0.38 & 0.46 & 0.44 & 0.33 & 0.36 & 0.18 & 0.73 \\
\hline$\# 23$ & 0.69 & 0.79 & 0.30 & 0.32 & 0.08 & 0.19 & 0.59 \\
\hline$\# 24$ & 0.12 & 0.28 & 0.21 & 0.38 & 0.32 & 0.14 & 0.59 \\
\hline$\# 25$ & 0.43 & 0.21 & 0.23 & 0.33 & 0.20 & 0.16 & 0.49 \\
\hline$\# 26$ & 0.56 & 0.21 & 0.15 & 0.38 & 0.24 & 0.20 & 0.42 \\
\hline$\# 27$ & 0.32 & 0.30 & 0.18 & 0.35 & 0.20 & 0.14 & 0.68 \\
\hline$\# 28$ & 0.60 & 0.17 & 0.13 & 0.32 & 0.20 & 0.14 & 0.46 \\
\hline$\# 29$ & 0.13 & 0.57 & 0.53 & 0.33 & 0.30 & 0.15 & 0.65 \\
\hline$\# 30$ & 0.52 & 0.26 & 0.16 & 0.36 & 0.15 & 0.18 & 0.57 \\
\hline \#31 & 0.33 & 0.18 & 0.23 & 0.37 & 0.22 & 0.18 & 0.41 \\
\hline$\# 32$ & 0.69 & 0.29 & 0.17 & 0.34 & 0.16 & 0.14 & 0.71 \\
\hline$\# 33$ & 0.41 & 0.21 & 0.24 & 0.32 & 0.16 & 0.11 & 0.51 \\
\hline$\# 34$ & 0.52 & 0.16 & 0.21 & 0.32 & 0.37 & 0.11 & 0.58 \\
\hline$\# 35$ & 0.48 & 0.40 & 0.42 & 0.31 & 0.23 & 0.11 & 0.75 \\
\hline \#36 & 0.46 & 0.19 & 0.30 & 0.30 & 0.16 & 0.11 & 0.51 \\
\hline$\# 37$ & 0.15 & 0.22 & 0.26 & 0.31 & 0.72 & 0.26 & 0.43 \\
\hline$\# 38$ & 0.63 & 0.39 & 0.41 & 0.47 & 0.31 & 0.08 & $\begin{array}{l}0.67 \\
\end{array}$ \\
\hline$\# 39$ & 0.35 & 0.22 & 0.22 & 0.28 & 0.72 & 0.25 & 0.54 \\
\hline$\# 40$ & 0.52 & 0.61 & 0.35 & 0.29 & 0.75 & 0.29 & 0.57 \\
\hline$\# 41$ & 0.46 & 0.29 & 0.42 & 0.41 & 0.80 & 0.28 & 0.86 \\
\hline$\# 42$ & 0.54 & 0.23 & 0.27 & 0.26 & 0.74 & 0.25 & 0.56 \\
\hline$\# 43$ & 0.33 & 0.21 & 0.17 & 0.37 & 0.73 & 0.26 & 0.63 \\
\hline$\# 44$ & 0.27 & 0.20 & 0.17 & 0.29 & 0.26 & 0.21 & 0.33 \\
\hline$\# 45$ & 0.27 & 0.37 & 0.32 & 0.35 & 0.75 & 0.25 & 0.69 \\
\hline \# 46 & 0.23 & 0.33 & 0.42 & 0.24 & 0.63 & 0.33 & 0.55 \\
\hline$\# 47$ & 0.47 & 0.28 & 0.24 & 0.21 & 0.35 & 0.08 & $\begin{array}{l}0.47 \\
\end{array}$ \\
\hline$\# 48$ & 0.30 & 0.24 & 0.17 & 0.21 & 0.44 & 0.07 & 0.45 \\
\hline$\# 49$ & 0.14 & 0.03 & 0.26 & 0.24 & 0.34 & 0.11 & 0.50 \\
\hline$\# 50$ & 0.45 & 0.50 & 0.53 & 0.29 & 0.42 & 0.06 & 0.73 \\
\hline$\# 51$ & 0.17 & 0.29 & 0.20 & 0.26 & 0.33 & 0.19 & 0.48 \\
\hline$\# 52$ & 0.45 & 0.41 & 0.28 & 0.29 & 0.33 & 0.10 & 0.56 \\
\hline$\# 53$ & 0.22 & 0.22 & 0.22 & 0.21 & 0.37 & 0.06 & 0.46 \\
\hline$\# 54$ & 0.22 & 0.19 & 0.22 & 0.23 & 0.37 & 0.07 & 0.71 \\
\hline$\# 55$ & 0.62 & 0.46 & 0.20 & 0.27 & 0.34 & 0.08 & 0.58 \\
\hline$\# 56$ & 0.79 & 0.25 & 0.51 & 0.20 & 0.17 & 0.18 & 0.79 \\
\hline$\# 57$ & 0.36 & 0.33 & 0.16 & 0.25 & 0.33 & 0.08 & 0.41 \\
\hline$\# 58$ & 0.77 & 0.47 & 0.34 & 0.39 & 0.38 & 0.20 & 0.23 \\
\hline \# 59 & 0.82 & 0.12 & 0.30 & 0.39 & 0.35 & 0.08 & 0.35 \\
\hline \#60 & 0.35 & 0.18 & 0.17 & 0.22 & 0.37 & 0.09 & 0.39 \\
\hline \# 61 & 0.15 & 0.15 & 0.10 & 0.24 & 0.12 & 0.21 & 0.06 \\
\hline$\# 62$ & 0.15 & 0.08 & 0.24 & 0.20 & 0.34 & 0.09 & 0.51 \\
\hline Average & 0.38 & 0.29 & 0.27 & 0.34 & 0.37 & 0.27 & 0.54 \\
\hline
\end{tabular}

$\mathrm{O}=\mathrm{own}$ effects equation; $\mathrm{C}=$ competitive effects equation; Average for the system $=$ Average of $\mathrm{R}^{2}$ from last row $=0.35$; and average $\mathrm{R}^{2}$ for the sales equation in the full model $=0.54$. 
Table A3: $R^{2}$ for the Full Model

\begin{tabular}{|c|c|c|c|c|c|c|c|c|c|c|c|c|c|c|c|}
\hline Brand & Distr & uution & Price & & Pron & tion & Adve & ising & Awal & ness & Cons & eration & Liki & & Volume \\
\hline & $\mathrm{O}$ & $\mathrm{C}$ & $\mathrm{O}$ & $\mathrm{C}$ & $\mathrm{O}$ & $\mathrm{C}$ & $\mathrm{O}$ & $\mathrm{C}$ & $\mathrm{O}$ & $\mathrm{C}$ & $\mathrm{O}$ & $\mathrm{C}$ & $\mathrm{O}$ & $\mathrm{C}$ & $\mathrm{O}$ \\
\hline$\# 1$ & 0.88 & 0.14 & 0.43 & 0.34 & 0.70 & 0.61 & 0.31 & 0.59 & 0.54 & 0.58 & 0.17 & 0.41 & 0.3 & 0.63 & 0.48 \\
\hline$\# 2$ & 0.29 & 0.19 & 0.48 & 0.50 & 0.48 & 0.64 & 0.29 & 0.58 & 0.19 & 0.72 & 0.19 & 0.38 & 0.3 & 0.76 & 0.64 \\
\hline$\# 3$ & 0.98 & 0.38 & 0.65 & 0.66 & 0.49 & 0.61 & 0.27 & 0.41 & 0.49 & 0.43 & 0.21 & 0.55 & 0.4 & 0.33 & 0.77 \\
\hline \# 4 & 0.83 & 0.50 & 0.38 & 0.31 & 0.24 & 0.54 & 0.27 & 0.42 & 0.19 & 0.53 & 0.48 & 0.38 & 0.5 & 0.42 & 0.28 \\
\hline$\# 5$ & 0.96 & 0.21 & 0.90 & 0.17 & 0.08 & 0.68 & 0.44 & 0.61 & 0.43 & 0.60 & 0.35 & 0.40 & 0.1 & 0.66 & 0.33 \\
\hline \# 6 & 0.96 & 0.22 & 0.55 & 0.52 & 0.55 & 0.62 & 0.33 & 0.50 & 0.37 & 0.52 & 0.26 & 0.39 & 0.1 & 0.26 & 0.69 \\
\hline$\# 7$ & 0.93 & 0.11 & 0.48 & 0.27 & 0.59 & 0.66 & 0.27 & 0.57 & 0.26 & 0.60 & 0.31 & 0.46 & 0.2 & 0.63 & 0.45 \\
\hline \# 8 & 0.90 & 0.20 & 0.41 & 0.37 & 0.53 & 0.67 & 0.37 & 0.60 & 0.76 & 0.61 & 0.75 & 0.46 & 0.6 & 0.71 & 0.68 \\
\hline \#9 & 0.80 & 0.27 & 0.87 & 0.18 & 0.65 & 0.63 & 0.39 & 0.55 & 0.32 & 0.60 & 0.50 & 0.38 & 0.1 & 0.73 & 0.81 \\
\hline$\# 10$ & 0.95 & 0.35 & 0.51 & 0.26 & 0.69 & 0.49 & 0.42 & 0.60 & 0.28 & 0.41 & 0.47 & 0.50 & 0.2 & 0.74 & 0.63 \\
\hline$\# 11$ & 0.41 & 0.23 & 0.83 & 0.10 & 0.29 & 0.67 & 0.57 & 0.61 & 0.31 & 0.61 & 0.21 & 0.41 & 0.1 & 0.75 & 0.49 \\
\hline$\# 12$ & 0.67 & 0.32 & 0.94 & 0.36 & 0.66 & 0.54 & 0.49 & 0.59 & 0.33 & 0.49 & 0.20 & 0.51 & 0.1 & 0.72 & 0.63 \\
\hline$\# 13$ & 0.66 & 0.14 & 0.89 & 0.29 & 0.34 & 0.62 & 0.47 & 0.60 & 0.28 & 0.54 & 0.21 & 0.47 & 0.2 & 0.68 & 0.73 \\
\hline$\# 14$ & 0.73 & 0.43 & 0.78 & 0.67 & 0.70 & 0.64 & 0.37 & 0.39 & 0.59 & 0.42 & 0.59 & 0.61 & 0.4 & 0.29 & 0.53 \\
\hline$\# 15$ & 0.40 & 0.19 & 0.72 & 0.16 & 0.58 & 0.64 & 0.38 & 0.61 & 0.29 & 0.60 & 0.32 & 0.41 & 0.3 & 0.68 & 0.88 \\
\hline$\# 16$ & 0.26 & 0.24 & 0.73 & 0.32 & 0.52 & 0.63 & 0.43 & 0.64 & 0.24 & 0.61 & 0.15 & 0.36 & 0.3 & 0.74 & 0.62 \\
\hline$\# 17$ & 0.42 & 0.16 & 0.14 & 0.41 & 0.46 & 0.63 & 0.39 & 0.60 & 0.36 & 0.58 & 0.19 & 0.40 & 0.2 & 0.65 & 0.55 \\
\hline$\# 18$ & 0.65 & 0.25 & 0.24 & 0.23 & 0.51 & 0.66 & 0.49 & 0.39 & 0.32 & 0.20 & 0.74 & 0.50 & 0.3 & 0.65 & 0.86 \\
\hline$\# 19$ & 0.33 & 0.38 & 0.86 & 0.20 & 0.33 & 0.66 & 0.56 & 0.58 & 0.71 & 0.52 & 0.60 & 0.73 & 0.2 & 0.74 & 0.69 \\
\hline$\# 20$ & 0.59 & 0.23 & 0.94 & 0.53 & 0.32 & 0.56 & 0.46 & 0.35 & 0.66 & 0.42 & 0.29 & 0.32 & 0.3 & 0.47 & 0.70 \\
\hline$\# 21$ & 0.23 & 0.57 & 0.45 & 0.50 & 0.48 & 0.67 & 0.42 & 0.30 & 0.74 & 0.45 & 0.49 & 0.25 & 0.4 & 0.22 & 0.68 \\
\hline$\# 22$ & 0.16 & 0.13 & 0.88 & 0.39 & 0.37 & 0.70 & 0.42 & 0.41 & 0.46 & 0.50 & 0.54 & 0.39 & 0.5 & 0.34 & 0.75 \\
\hline$\# 23$ & 0.97 & 0.36 & 0.59 & 0.19 & 0.25 & 0.66 & 0.49 & 0.30 & 0.74 & 0.41 & 0.82 & 0.12 & 0.1 & 0.30 & 0.66 \\
\hline$\# 24$ & 0.94 & 0.60 & 0.38 & 0.21 & 0.55 & 0.60 & 0.57 & 0.27 & 0.55 & 0.68 & 0.52 & 0.52 & 0.3 & 0.57 & 0.75 \\
\hline$\# 25$ & 0.13 & 0.41 & 0.50 & 0.20 & 0.41 & 0.63 & 0.40 & 0.36 & 0.49 & 0.42 & 0.46 & 0.41 & 0.4 & 0.44 & 0.58 \\
\hline$\# 26$ & 0.97 & 0.47 & 0.23 & 0.28 & 0.44 & 0.65 & 0.50 & 0.32 & 0.61 & 0.43 & 0.52 & 0.30 & 0.4 & 0.32 & 0.49 \\
\hline$\# 27$ & 0.25 & 0.18 & 0.22 & 0.41 & 0.21 & 0.68 & 0.30 & 0.59 & 0.38 & 0.42 & 0.46 & 0.23 & 0.3 & 0.42 & 0.71 \\
\hline$\# 28$ & 0.94 & 0.17 & 0.70 & 0.90 & 0.46 & 0.64 & 0.30 & 0.36 & 0.69 & 0.42 & 0.52 & 0.28 & 0.4 & 0.43 & 0.52 \\
\hline$\# 29$ & 0.98 & 0.47 & 0.41 & 0.79 & 0.27 & 0.68 & 0.43 & 0.37 & 0.50 & 0.45 & 0.72 & 0.34 & 0.5 & 0.23 & 0.73 \\
\hline$\# 30$ & 1.00 & 0.41 & 0.77 & 0.30 & 0.62 & 0.62 & 0.47 & 0.54 & 0.63 & 0.54 & 0.51 & 0.29 & 0.2 & 0.38 & 0.60 \\
\hline \#31 & 0.97 & 0.46 & 0.33 & 0.38 & 0.35 & 0.67 & 0.57 & 0.58 & 0.48 & 0.47 & 0.49 & 0.28 & 0.3 & 0.32 & 0.68 \\
\hline$\# 32$ & 0.96 & 0.48 & 0.53 & 0.27 & 0.55 & 0.63 & 0.40 & 0.28 & 0.72 & 0.42 & 0.41 & 0.24 & 0.2 & 0.42 & 0.75 \\
\hline$\# 33$ & 0.88 & 0.48 & 0.55 & 0.21 & 0.42 & 0.67 & 0.43 & 0.36 & 0.56 & 0.43 & 0.23 & 0.77 & 0.2 & 0.42 & 0.61 \\
\hline$\# 34$ & 0.90 & 0.52 & 0.82 & 0.25 & 0.34 & 0.66 & 0.36 & 0.37 & 0.56 & 0.43 & 0.26 & 0.43 & 0.1 & 0.46 & 0.65 \\
\hline \#35 & 0.11 & 0.49 & 0.65 & 0.42 & 0.49 & 0.64 & 0.23 & 0.34 & 0.52 & 0.43 & 0.50 & 0.30 & 0.4 & 0.26 & 0.79 \\
\hline$\# 36$ & 0.15 & 0.43 & 0.24 & 0.96 & 0.63 & 0.59 & 0.31 & 0.20 & 0.54 & 0.39 & 0.30 & 0.53 & 0.3 & 0.38 & 0.64 \\
\hline$\# 37$ & 0.98 & 0.59 & 0.25 & 0.34 & 0.36 & 0.44 & 0.43 & 0.48 & 0.17 & 0.44 & 0.26 & 0.76 & 0.2 & 0.39 & 0.82 \\
\hline$\# 38$ & 0.99 & 0.57 & 0.39 & 0.39 & 0.38 & 0.54 & 0.41 & 0.58 & 0.77 & 0.57 & 0.57 & 0.42 & 0.6 & 0.48 & 0.71 \\
\hline$\# 39$ & 0.92 & 0.47 & 0.40 & 0.45 & 0.56 & 0.50 & 0.39 & 0.47 & 0.42 & 0.32 & 0.34 & 0.77 & 0.4 & 0.45 & 0.60 \\
\hline$\# 40$ & 0.99 & 0.45 & 0.44 & 0.31 & 0.52 & 0.45 & 0.27 & 0.47 & 0.65 & 0.48 & 0.70 & 0.80 & 0.5 & 0.42 & 0.63 \\
\hline$\# 41$ & 0.85 & 0.49 & 0.57 & 0.36 & 0.36 & 0.46 & 0.35 & 0.39 & 0.54 & 0.45 & 0.28 & 0.81 & 0.4 & 0.42 & 0.86 \\
\hline$\# 42$ & 0.89 & 0.47 & 0.85 & 0.36 & 0.44 & 0.45 & 0.52 & 0.39 & 0.61 & 0.39 & 0.35 & 0.80 & 0.4 & 0.40 & 0.60 \\
\hline$\# 43$ & 0.85 & 0.58 & 0.87 & 0.35 & 0.44 & 0.43 & 0.41 & 0.45 & 0.42 & 0.43 & 0.13 & 0.75 & 0.5 & 0.44 & 0.68 \\
\hline$\# 44$ & 0.80 & 0.44 & 0.68 & 0.45 & 0.58 & 0.56 & 0.43 & 0.33 & 0.29 & 0.39 & 0.55 & 0.60 & 0.5 & 0.47 & 0.66 \\
\hline$\# 45$ & 0.90 & 0.43 & 0.74 & 0.39 & 0.43 & 0.46 & 0.52 & 0.39 & 0.41 & 0.39 & 0.43 & 0.77 & 0.4 & 0.38 & 0.73 \\
\hline$\# 46$ & 1.00 & 0.41 & 0.67 & 0.34 & 0.63 & 0.44 & 0.41 & 0.39 & 0.35 & 0.41 & 0.42 & 0.76 & 0.6 & 0.43 & 0.78 \\
\hline$\# 47$ & 0.97 & 0.63 & 0.44 & 0.41 & 0.44 & 0.46 & 0.33 & 0.48 & 0.43 & 0.39 & 0.47 & 0.76 & 0.5 & 0.47 & 0.68 \\
\hline$\# 48$ & 0.42 & 0.49 & 0.34 & 0.46 & 0.33 & 0.53 & 0.58 & 0.33 & 0.52 & 0.27 & 0.15 & 0.47 & 0.1 & 0.46 & 0.65 \\
\hline$\# 49$ & 0.87 & 0.48 & 0.74 & 0.28 & 0.40 & 0.64 & 0.54 & 0.47 & 0.45 & 0.25 & 0.45 & 0.56 & 0.3 & 0.48 & 0.69 \\
\hline$\# 50$ & 0.16 & 0.79 & 0.15 & 0.62 & 0.50 & 0.24 & 0.22 & 0.36 & 0.34 & 0.15 & 0.39 & 0.58 & 0.4 & 0.41 & 0.71 \\
\hline$\# 51$ & 0.99 & 0.40 & 0.55 & 0.49 & 0.80 & 0.61 & 0.50 & 0.42 & 0.55 & 0.37 & 0.57 & 0.52 & 0.5 & 0.30 & 0.77 \\
\hline$\# 52$ & 0.50 & 0.42 & 0.84 & 0.16 & 0.31 & 0.53 & 0.41 & 0.56 & 0.19 & 0.37 & 0.44 & 0.43 & 0.2 & 0.22 & 0.51 \\
\hline$\# 53$ & 0.95 & 0.57 & 0.37 & 0.49 & 0.52 & 0.58 & 0.38 & 0.31 & 0.52 & 0.34 & 0.51 & 0.43 & 0.3 & 0.20 & 0.67 \\
\hline$\# 54$ & 0.93 & 0.48 & 0.42 & 0.32 & 0.26 & 0.57 & 0.45 & 0.38 & 0.27 & 0.26 & 0.28 & 0.42 & 0.6 & 0.11 & 0.66 \\
\hline
\end{tabular}




\begin{tabular}{|l|l|l|l|l|l|l|l|l|l|l|l|l|l|l|l|l|l|l|l|}
\hline Brand & Distribution & \multicolumn{2}{l|}{ Price } & \multicolumn{2}{l|}{ Promotion } & \multicolumn{2}{l|}{ Advertising } & \multicolumn{2}{l|}{ Awareness } & \multicolumn{2}{l|}{ Consideration } & \multicolumn{2}{l|}{ Liking } & \multicolumn{2}{l|}{ Volume } \\
\hline & $\mathrm{O}$ & $\mathrm{C}$ & $\mathrm{O}$ & $\mathrm{C}$ & $\mathrm{O}$ & $\mathrm{C}$ & $\mathrm{O}$ & $\mathrm{C}$ & $\mathrm{O}$ & $\mathrm{C}$ & $\mathrm{O}$ & $\mathrm{C}$ & $\mathrm{O}$ & $\mathrm{C}$ & $\mathrm{O}$ \\
\hline \# 55 & 0.95 & 0.68 & 0.18 & 0.19 & 0.50 & 0.56 & 0.41 & 0.38 & 0.29 & 0.32 & 0.25 & 0.46 & 0.4 & 0.17 & 0.72 \\
\hline \# 56 & 0.99 & 0.48 & 0.49 & 0.08 & 0.49 & 0.55 & 0.40 & 0.37 & 0.69 & 0.39 & 0.55 & 0.52 & 0.4 & 0.69 & 0.75 \\
\hline \# 57 & 0.99 & 0.42 & 0.47 & 0.28 & 0.78 & 0.71 & 0.23 & 0.31 & 0.82 & 0.24 & 0.35 & 0.59 & 0.5 & 0.30 & 0.86 \\
\hline \# 58 & 0.98 & 0.39 & 0.55 & 0.12 & 0.53 & 0.61 & 0.47 & 0.45 & 0.47 & 0.39 & 0.41 & 0.41 & 0.5 & 0.48 & 0.69 \\
\hline \# 59 & 0.94 & 0.37 & 0.65 & 0.25 & 0.61 & 0.44 & 0.33 & 0.34 & 0.80 & 0.42 & 0.59 & 0.51 & 0.4 & 0.29 & 0.70 \\
\hline \# 60 & 0.84 & 0.50 & 0.76 & 0.38 & 0.56 & 0.53 & 0.13 & 0.26 & 0.83 & 0.43 & 0.22 & 0.43 & 0.4 & 0.33 & 0.70 \\
\hline \# 61 & 0.96 & 0.41 & 0.50 & 0.45 & 0.36 & 0.57 & 0.29 & 0.51 & 0.48 & 0.30 & 0.41 & 0.43 & 0.4 & 0.48 & 0.75 \\
\hline \# 62 & 0.83 & 0.46 & 0.72 & 0.48 & 0.53 & 0.50 & 0.39 & 0.34 & 0.18 & 0.23 & 0.13 & 0.38 & 0.3 & 0.47 & 0.80 \\
\hline Averag & $\mathbf{0 . 7 5}$ & $\mathbf{0 . 4 0}$ & $\mathbf{0 . 5 6}$ & $\mathbf{0 . 3 7}$ & $\mathbf{0 . 4 7}$ & $\mathbf{0 . 5 8}$ & $\mathbf{0 . 4 0}$ & $\mathbf{0 . 4 4}$ & $\mathbf{0 . 4 8}$ & $\mathbf{0 . 4 4}$ & $\mathbf{0 . 4 0}$ & $\mathbf{0 . 4 8}$ & $\mathbf{0 . 3}$ & $\mathbf{0 . 4 6}$ & $\mathbf{0 . 6 7}$ \\
\hline
\end{tabular}

1. $\mathrm{O}=$ own effects equation; $\mathrm{C}=$ competitive effects equation

2. Average for the system $=$ Average of $\mathrm{R}$-squared of the last row $=0.49$

3. Average for the sales equation in the full model $=0.67$ from last row 
Table A4. Elasticities of Sales to Marketing Mix and Mindset Metrics

\begin{tabular}{|c|c|c|c|c|c|c|c|}
\hline Brand & Price & Promotions & Advertising & Distribution & Ad Awareness & Consideration & Liking \\
\hline$\# 1$ & -0.47 & 0.46 & 0.07 & 1.12 & 0.53 & 0.96 & $0.01(\mathrm{~ns})$ \\
\hline$\# 2$ & -0.48 & 0.12 & $(-0.01)(\mathrm{ns})$ & $3.83(\mathrm{~ns})$ & $0.12(\mathrm{~ns})$ & 0.82 & $-0.62(\mathrm{~ns})$ \\
\hline$\# 3$ & -2.93 & 0.40 & 0.08 & $3.11(\mathrm{~ns})$ & 0.17 & $-0.42(\mathrm{~ns})$ & $0.1(\mathrm{~ns})$ \\
\hline$\# 4$ & -0.59 & 0.09 & 0.03 & 2.55 & 0.13 (ns) & $-0.25(\mathrm{~ns})$ & $-0.98(\mathrm{~ns})$ \\
\hline$\# 5$ & -2.99 & $0.04(\mathrm{~ns})$ & $-0.01(\mathrm{~ns})$ & 2.44 & $0.02(\mathrm{~ns})$ & 1.28 & 0.76 \\
\hline$\# 6$ & -3.30 & $0.01(\mathrm{~ns})$ & $0.03(\mathrm{~ns})$ & $2.36(\mathrm{~ns})$ & 0.09 (ns) & 0.04 (ns) & $-0.34(\mathrm{~ns})$ \\
\hline$\# 7$ & -0.61 & 0.12 & 0.0 & $2.56(\mathrm{~ns})$ & 0.13 (ns) & $-0.30(\mathrm{~ns})$ & 0 (ns) \\
\hline$\# 8$ & $-0.40(\mathrm{~ns})$ & 0.10 & $0.02(\mathrm{~ns})$ & 0.92 & 0.14 (ns) & 0.07 & 0.18 \\
\hline$\# 9$ & $-0.22(\mathrm{~ns})$ & 0.11 & $0.01(\mathrm{~ns})$ & 1.11 & 0.24 & 1.19 & 1.24 \\
\hline$\# 10$ & $-0.12(\mathrm{~ns})$ & 0.39 & 0.05 & 2.35 & 0.03 (ns) & 1.42 & $-0.18(\mathrm{~ns})$ \\
\hline$\# 11$ & -5.55 & 0.26 & 0.06 & $2.22(\mathrm{~ns})$ & 0.33 & $-0.35(\mathrm{~ns})$ & 0.08 (ns) \\
\hline$\# 12$ & -2.79 & 0.32 & $0.00(\mathrm{~ns})$ & $1.22(\mathrm{~ns})$ & $-0.01(\mathrm{~ns})$ & 0.92 & 1.45 \\
\hline$\# 13$ & -4.25 & $0.10(\mathrm{~ns})$ & 0.12 & 2.47 & 0.74 & $0.05(\mathrm{~ns})$ & 0.58 \\
\hline$\# 14$ & -2.68 & 0.18 & 0.09 & 2.55 & 0.14 & $-0.52(\mathrm{~ns})$ & 1.19 \\
\hline$\# 15$ & -3.97 & 0.26 & 0.06 & $2.66(\mathrm{~ns})$ & $0.08(\mathrm{~ns})$ & $-0.21(\mathrm{~ns})$ & 0.4 \\
\hline$\# 16$ & $-0.34(\mathrm{~ns})$ & $0.02(\mathrm{~ns})$ & $-0.02(\mathrm{~ns})$ & 2.56 & 0.12 & 1.35 & 0.81 \\
\hline$\# 17$ & -0.59 & 0.39 & 0.05 & $3.08(\mathrm{~ns})$ & 0.10 (ns) & 0.03 (ns) & $-1.41(\mathrm{~ns})$ \\
\hline$\# 18$ & -0.56 & $0.08(\mathrm{~ns})$ & 0.03 (ns) & 1.34 & $0.12(\mathrm{~ns})$ & 0.46 & 0.82 \\
\hline$\# 19$ & -2.93 & 0.10 & 0.09 & 1.21 & 0.13 & $0.05(\mathrm{~ns})$ & $-0.29(\mathrm{~ns})$ \\
\hline$\# 20$ & -2.76 & $0.03(\mathrm{~ns})$ & 0.02 & 2.45 (ns) & 0.15 & $0.08(\mathrm{~ns})$ & 1.16 \\
\hline$\# 21$ & $-0.31(\mathrm{~ns})$ & 0.05 & 0.04 & 2.36 & 0.47 & 0.89 & 1.66 \\
\hline$\# 22$ & -2.94 & 0.16 & 0.06 & 1.45 (ns) & 0.06 (ns) & 1.61 & 2.81 \\
\hline$\# 23$ & -0.01 & 0.22 & 0.06 & 2.59 & 0.70 & 1.48 & $0(\mathrm{~ns})$ \\
\hline$\# 24$ & $-0.33(\mathrm{~ns})$ & 0.01 & $-0.01(\mathrm{~ns})$ & 2.85 & 0.12 & 0.02 & 0.16 \\
\hline$\# 25$ & -2.94 & $0.01(\mathrm{~ns})$ & 0.06 & $2.59(\mathrm{~ns})$ & 0.67 & 1.14 & 0.66 \\
\hline$\# 26$ & $-0.24(\mathrm{~ns})$ & 0.03 & 0.05 & 2.87 & 0.00 (ns) & 0.05 & 0.03 (ns) \\
\hline$\# 27$ & -0.57 & 0.25 & 0.05 & $2.75(\mathrm{~ns})$ & 0.70 & 1.57 & 0.71 \\
\hline$\# 28$ & -0.66 & 0.39 & $0.00(\mathrm{~ns})$ & 2.72 & 0.14 & 1.86 & $-0.01(\mathrm{~ns})$ \\
\hline$\# 29$ & 0.00 & 0.08 & 0.02 & 2.79 & $-0.02(\mathrm{~ns})$ & $1.77(\mathrm{~ns})$ & 0.54 \\
\hline$\# 30$ & -2.83 & 0.59 & 0.08 & 0.96 (ns) & 0.64 & 0.09 & $0.01(\mathrm{~ns})$ \\
\hline$\# 31$ & $-0.44(\mathrm{~ns})$ & 0.95 & 0.03 (ns) & 2.97 & 0.04 (ns) & $0(\mathrm{~ns})$ & $0(\mathrm{~ns})$ \\
\hline$\# 32$ & -3.19 & 0.62 & 0.06 & 3.88 (ns) & 1.07 & $-0.64(\mathrm{~ns})$ & 0.71 \\
\hline$\# 33$ & -3.00 & 0.05 & $-0.00(\mathrm{~ns})$ & 0.11 & 0.13 (ns) & $-0.44(\mathrm{~ns})$ & $0.01(\mathrm{~ns})$ \\
\hline$\# 34$ & $\begin{array}{l}-0.62 \\
\end{array}$ & 0.07 & 0.12 & $3.24(\mathrm{~ns})$ & 0.60 & 0.78 & 0.56 \\
\hline$\# 35$ & -2.58 & -0.03 & 0.08 & 2.83 & 0.40 & 0.63 & $5.12(\mathrm{~ns})$ \\
\hline$\# 36$ & $-0.21(\mathrm{~ns})$ & 0.90 & 0.03 (ns) & 0.37 (ns) & 0.53 & 0.05 (ns) & 2.62 \\
\hline$\# 37$ & $-0.17(\mathrm{~ns})$ & 0.09 & 0.03 & $2.69(\mathrm{~ns})$ & 0.13 & $0.01(\mathrm{~ns})$ & $0.01(\mathrm{~ns})$ \\
\hline$\# 38$ & 0.00 & -0.01 & $0.00(\mathrm{~ns})$ & 2.90 & 1.38 & 0.81 & 0.8 \\
\hline$\# 39$ & -2.76 & $0.04(\mathrm{~ns})$ & $0.02(\mathrm{~ns})$ & $3.22(\mathrm{~ns})$ & 0.14 (ns) & $-0.33(\mathrm{~ns})$ & 0.79 \\
\hline$\# 40$ & $-0.33(\mathrm{~ns})$ & $0.10(\mathrm{~ns})$ & 0.03 & 2.99 & 0.49 & 0.84 & 2.4 \\
\hline$\# 41$ & -2.73 & 0.78 & 0.04 & 0.64 (ns) & 0.65 & 0.87 & $7.71(\mathrm{~ns})$ \\
\hline$\# 42$ & -2.87 & 0.19 & 0.04 & 2.81 & 0.44 & $-0.46(\mathrm{~ns})$ & $0.06(\mathrm{~ns})$ \\
\hline$\# 43$ & -2.87 & 0.91 & 0.06 & 2.83 & 0.47 & $0.02(\mathrm{~ns})$ & $-0.01(\mathrm{~ns})$ \\
\hline$\# 44$ & -2.94 & 0.07 & $-0.01(\mathrm{~ns})$ & 2.76 & 0.15 & 0.02 & 0.5 \\
\hline$\# 45$ & $-0.12(\mathrm{~ns})$ & 0.29 & 0.06 & $2.78(\mathrm{~ns})$ & 0.88 & 0.82 & 0.77 \\
\hline$\# 46$ & -0.50 & 0.00 & $0.00(\mathrm{~ns})$ & $2.81(\mathrm{~ns})$ & 0.05 (ns) & 0.73 & $-8.2(\mathrm{~ns})$ \\
\hline$\# 47$ & $-0.38(\mathrm{~ns})$ & 0.00 & $0.01(\mathrm{~ns})$ & 2.87 & 0.14 & 0.88 & 1.31 \\
\hline$\# 48$ & -3.50 & 0.22 & 0.08 & 2.78 & 0.22 & $-0.69(\mathrm{~ns})$ & 0.45 \\
\hline$\# 49$ & -3.65 & 0.14 & 0.05 & $2.67(\mathrm{~ns})$ & 0.09 (ns) & 0 & $0.01(\mathrm{~ns})$ \\
\hline$\# 50$ & -3.77 & 0.09 & $0.03(\mathrm{~ns})$ & 2.96 & $0.02(\mathrm{~ns})$ & 0.64 & 1.12 \\
\hline$\# 51$ & -2.89 & $0.06(\mathrm{~ns})$ & $-0.01(\mathrm{~ns})$ & 2.81 & 0.52 & 0.58 & 1.1 \\
\hline$\# 52$ & -3.43 & 0.09 (ns) & 0.04 & $2.03(\mathrm{~ns})$ & 0.04 (ns) & 0.42 & 1.11 \\
\hline$\# 53$ & $-0.24(\mathrm{~ns})$ & 0.72 & 0.03 & 0.23 & 0.22 & 0.59 & 1.89 \\
\hline$\# 54$ & $-0.27(\mathrm{~ns})$ & $0.10(\mathrm{~ns})$ & $0.03(\mathrm{~ns})$ & 2.81 & $-0.01(\mathrm{~ns})$ & $-0.51(\mathrm{~ns})$ & $-0.01(\mathrm{~ns})$ \\
\hline$\# 55$ & -0.60 & $0.08(\mathrm{~ns})$ & $0.00(\mathrm{~ns})$ & 2.73 (ns) & 0.09 (ns) & $0.09(\mathrm{~ns})$ & 0.02 (ns) \\
\hline
\end{tabular}




\begin{tabular}{|l|l|l|l|l|l|l|l|}
\hline \# 56 & 0.01 & 0.47 & 0.04 & 2.80 & $0.14(\mathrm{~ns})$ & 1.33 & 1.28 \\
\hline \# 57 & -3.73 & 0.37 & $0.00(\mathrm{~ns})$ & 2.97 & 0.49 & $-0.45(\mathrm{~ns})$ & 1.02 \\
\hline \# 58 & -2.84 & 1.48 & $0.00(\mathrm{~ns})$ & 2.84 & $0.07(\mathrm{~ns})$ & 0.14 & 0.76 \\
\hline \# 59 & -3.97 & 0.83 & 0.05 & $3.44(\mathrm{~ns})$ & 0.47 & $0(\mathrm{~ns})$ & $-0.01(\mathrm{~ns})$ \\
\hline \# 60 & -0.62 & 0.89 & 0.04 & 2.81 & 0.30 & $-0.50(\mathrm{~ns})$ & $0.31(\mathrm{~ns})$ \\
\hline \# 61 & -2.92 & 0.66 & 0.05 & 2.84 & 0.44 & $-0.31(\mathrm{~ns})$ & 0.845 \\
\hline \# 62 & 0.01 & 0.61 & $0.01(\mathrm{~ns})$ & $2.85(\mathrm{~ns})$ & $0.09(\mathrm{~ns})$ & 0.10 & $0(\mathrm{~ns})$ \\
\hline Median* & -0.642 & 0.120 & 0.037 & 2.740 & 0.149 & 0.093 & 0.519 \\
\hline Average* & -1.734 & 0.277 & 0.036 & 2.424 & 0.289 & 0.374 & 0.590 \\
\hline Median** & -2.830 & 0.220 & 0.050 & 2.783 & 0.454 & 0.820 & 0.815 \\
\hline Average** & -2.208 & 0.335 & 0.057 & 2.381 & 0.444 & 0.782 & 1.034 \\
\hline
\end{tabular}

*Calculated including significant and insignificant estimates.

**Calculated including only the significant estimates. 


\section{Endnotes}

1 Research on the hierarchy of effects shows that evidence on the exact sequence of effects is mixed (Franses and Vriens 2004; Vakratsas and Ambler 1999; Zinkhan and Fornell 1989; Zufryden 1996). A likely explanation is that the sequence depends on a number of product category and consumer factors that vary across studies (Batra and Vanhonacker 1988). We therefore decided to adopt a modeling approach that does not impose a sequence of effects but instead is able to capture multiple interactions among our measures, including the mindset measures.

2 Although the actual measure of brand performance is purchases, as registered by consumers, and not sales, as registered by stores, we use the word "sales" in the remainder of the paper.

3 We follow Pauwels, Hanssens, and Siddarth (2002) in adopting static weights (i.e., average share across the sample) rather than dynamic (current-period) weights to compute the weighted prices.

4 VARX model specification requires a test on the statonarity of each endogenous variable. We use the Augmented Dickey Fuller (ADF) test to verify the presence of unit roots in the data, applying the iterative procedure proposed in Enders (2004, pp. 181-183) to decide whether to include a deterministic trend in the test. When the test confirms the existence of a unit root we treat the variable as evolving. When more than one variable in a VARX system is found to be evolving, we implement Johansen's cointegration test to capture a possible long-run equilibrium among the evolving variables (Dekimpe and Hanssens 1999; Srinivasan et al. 2000).

5 In GFEVD an initial shock is allowed to (but need not, depending on the size of the corresponding residual correlation) affect all other endogenous variables instantaneously. This has recently been applied in a marketing setting by Nijs, Srinivasan and Pauwels (2007).

6 Purchase inertia means that sales gains now result in sales gains later. We can also interpret this as 'behavioral loyalty': consumers tend to repeat past buying decisions. Purchase inertia may occur through several mechanisms, including feedback from purchases to mindset metrics (e.g. consumers who buy the product, like it, and then repurchase) and from purchases to marketing actions (e.g. a purchase increase allows the brand manager to spend more on promoting the brand, which in turn increases purchases). Note that purchase inertia is unrelated to the unexplained residuals. Our model explains the endogenous variable 'sales' by its own past and the past of the other endogenous variables. An interesting analogy is the 'past purchase loyalty' in the Guadagni and Little (1983) model: this variable explains a substantial part of choice and is not related to the model's residual.

7 Previous studies have shown that a period of 26 weeks ( 6 months) is sufficient for stationary series in consumer-packaged goods to capture dynamic effects (Pauwels and Srinivasan 2004; Srinivasan et al. 2004).

8 Adding either brand awareness or purchase intention, or replacing an included mindset metric with these variables, did not improve model fit.

$9 \quad$ While our model allows for dual causality between purchases and the explanatory variables, Granger causality tests show that marketing actions and mindset metrics more often Granger cause purchases than vice versa. Awareness, consideration and liking Granger cause purchases for respectively $73 \%$, $71 \%$ and $63 \%$ of all brands, while purchases Granger causes the mindset metrics for respectively $52 \%$, $60 \%$ and $51 \%$ of all brands. 